The Economic and Social Review, Vol. 34, No. 2, Summer/Autumn, 2003, pp. 109-143

\title{
An Analysis of the Journal Article Output of Irish-based Economists, 1970 to 2001
}

\author{
ALAN BARRETT \\ The Economic and Social Research Institute, Dublin \\ BRIAN LUCEY* \\ Trinity College Dublin
}

\begin{abstract}
This paper provides, for the first time, a comprehensive analysis of the journal article output of Irish-based economists over a thirty-year period. Using EconLit data, and supplementing where necessary, we provide details of the journals wherein Irish-based economists have published, provide details of the publishing histories of high volume publishers and discuss the evolving productivity profile of Irish-based economists. Our evidence shows that in general Irish-based economists have greatly increased the levels of output in the 1990s, but that this may have been at the expense of quality.
\end{abstract}

\section{INTRODUCTION}

Oing back to the 1970s (Moore, 1973), rankings of Economics departments Tin the United States have been published from time to time (Graves et al. 1982 and 1984; Hirsch et al. 1984; Tschirhart, 1989; Scott and Mitias, 1996). The basic methodology used is to measure the research output of each department through a count of journal articles, typically adjusting for quality of journal, numbers of pages etc. While most of the papers mentioned focus on departmental rankings, Scott and Mitias (1996) use their data to produce a "Hall of Fame", that is, a ranking of individuals based on journal output. More

We wish to thank a number of people for their invaluable contributions to this paper. In particular, the Editor and two anonymous referees deserve special notice. We also wish to thank the then president of the Irish Economic Association, Frances Ruane, for her initial encouragement and constant support in relation to this work.

* Corresponding author; e-mail address is blucey@tcd.ie 
recently, Kalaitzidakis et al. (1999) have produced a similar type of ranking for European institutions. So far as the authors are aware no such paper has focused on the Irish profession.

In this paper, we analyse data on the journal output of economists working in Irish institutions and produce rankings of individual economists based on this data. There are a number of reasons for doing this. We hope that it will be of interest to the members of the Irish economic profession, to see how productive the profession is in Ireland. In particular, as we present data and rankings for the 1970s, the 1980s and the 1990s, it will be possible to see how the profession has developed. Our a priori expectation was to see an increase in output and also a greater internationalisation of output, in the sense of a movement towards international journals relative to domestic outlets.

It will also be possible to assess whether Ireland's output of economics journal articles is dominated by a few highly prolific individuals or is more dispersed. Again, given the time periods, we can examine how this has changed over time. An additional benefit to the exercise is to provide members of the Association with a profession-wide benchmark against which to assess their own productivity or to set professional goals.

The paper is structured as follows. In Section II, we review the literature in this area. In Section III, we describe how our data set was assembled. In Section IV, we discuss how the rankings are constructed and we present the findings. In Section V, we offer some conclusions.

\section{LITERATURE REVIEW}

As discussed in the Introduction, papers of this type go back, to our knowledge, to Moore (1973). As the methods employed in the succeeding papers are broadly similar, we only review the more recent examples.

Scott and Mitias (1996) produce rankings of US Economics Departments based on the number of pages published between 1984 and 1993. It should be noted that they use number of pages rather than number of articles, on the assumption that larger articles represent larger research output. This assumption is of course questionable. Their first set of results is based on the "top" thirty-six journals. Inverted comas are used because there is disagreement over which thirty-six journals should be included. Their choice is motivated mainly by a desire to be consistent with the earlier work of Graves et al. (1982 and 1984) and Hirsch et al. (1984). In order to take account of co-authorships, each co-author was allocated $1 / n$ pages where $n$ is the number of co-authors. They also adjusted the page numbers to take account of the fact that journals differ in number of words per page. 
The use of thirty-six journals suffers from the weakness that pages in the top journals should not be counted as if they were of the same quality as pages in the lower ranking of the thirty-six. For this reason, Scott and Mitias present a ranking based on pages in the top five journals. The ones they choose as the top five are as follows: the American Economic Review, Econometrica, Journal of Political Economy, Quarterly Journal of Economics and Review of Economics and Statistics. As with the list of thirty-six journals, there would not necessarily be complete agreement on the top five; one could make a good case, for example, for including the Economic Journal.

In addition to presenting rankings of departments based on the above criteria, Scott and Mitias also look at pages per faculty member, the concentration of output within faculties and the ranking of individuals as opposed to departments. They find that the top three departments based on the flow of pages in the top thirty-six journals between 1984 and 1993 is as follows: (1) Harvard, (2) Chicago and (3) Pennsylvania. When they consider the top five journals the ranking is: (1) MIT, (2) Harvard and (3) Princeton. For individuals, the top three based on thirty-six journals are: (1) Stephen Turnovsky, (2) Kip Viscusi and (3) Lawrence Summers. Based on the top five journals, the ranking is: (1) David Card, (2) Jean Tirole and (3) Lawrence Summers.

Kalaitzidakis et al. (1999) perform a very similar exercise but look at European departments. They choose to use ten journals, as opposed to the thirty-six and five of Scott and Mitias. Their ten are as follows: American Economic Review, Econometrica, Journal of Political Economy, Quarterly Journal of Economics, Journal of Monetary Economics, Journal of Economic Theory, Review of Economic Studies, Review of Economics and Statistics, The Economic Journal and the European Economic Review. The first nine of these are justified by reference to a number of journal quality rankings. The inclusion of the European Economic Review is justified because of its importance as an outlet for European economists.

Like Scott and Mitias, Kalaitzidakis et al. use page numbers and adjust for number of co-authors and page size. Whereas Scott and Mitias adjust for quality by restricting the analysis to the top five journals, Kalaitzidakis et al. use an "impact adjusted citations per character" index; this is based on citations and is taken from Laband and Piette (1994). Their results ranked the London School of Economics as first in Europe, followed by Tel Aviv and Oxford. Of the Irish institutions, Maynooth ranked highest on the core measure but University College Dublin ranked higher on other measures.

Lest it be argued that economics, with its emphasis on the allocation of scarce resources (journal spaces) among competing agents (authors) is the only social science concerned with this issue, the work of Hennessey and Hogan 
(2000) can demonstrate otherwise. They examine the work of "Irish" researchers in an area of psychology, facing many of the same issues of data, definition of sample universe, and choice among competing metrics of quality as we face.

Similarly, amongst many sub-disciplines of economics there exist sector specific analyses of the productivity of researchers, again demonstrating in their analyses the difficulty of selecting metrics, deciding on coverage and so forth. Examples from the finance literature include Zivney and Bertin (1992) who examined the journal publication output of all graduates of US finance doctoral programmes over a twenty-five-year period. Borokhovich and Cheung (2000) update these analyses. Borokhovich et al. (1995) examine the attributes that determine success (defined as high levels of publications in core journals and/or high levels of citations in the Social Science Citation Index) in finance departments and research groupings. All of these, and many others, have ultimately taken their lead from the approach of Moore, discussed above. As a final note on the literature in this area, we should point out national-level analyses using EconLit, like the present one, have been undertaken for Brazil (Faria, 1998), France (Combes and Linnemer, 2000) and New Zealand (King, 2000).

\section{DATA}

Before describing how we assembled our data, it is worth stating what our objective is as this will determine the data assembling process. Our objective was to conduct a quantitative analysis of the academic journal output of the economics profession in Ireland over the last thirty years. In order to do this, we needed to assemble the publication records of people who have worked, or are working, in Irish institutions.

Before outlining further how we assembled the data, let us clarify some of the things that we were not attempting. We were not trying to compile the records of all Irish economists; rather, our focus was on the economics profession in Ireland, whether practiced by Irish or non-Irish economists. We were also not trying to compile the full publication records of Irish-based economists. We restrict our attention to journal articles in journals that are, or have been, cited in EconLit. In this way, the selection of journals is determined by the selection procedures of the American Economics Association and not by us. Some might argue that such a focus provides only a partial insight into the output of the profession. We respond by saying that the profession tends to give greatest weight to journal articles when conducting research assessments and so we are being consistent with that approach. This 
is not to downplay the importance of other sources of scholarly and professional communication, merely to recognise the perception of a "gold standard", a similar approach to that prevailing in other disciplines.

While our focus on EconLit cited journal articles will lead us to omit books, book chapters, articles in professional and other journals (such as the The Economic and Social Research Institute's (ESRI) Quarterly Economic Commentary) our greater concern relates to the omission of refereed papers in, for example, statistical or sociological journals. We decided to restrict our attention to EconLit so that the paper would be about the output of economic articles by Irish-based economists. For individuals who publish across the disciplines therefore, the total number of articles noted below will be an underestimate of their overall productivity. A logical extension of this research then would be a collection of all scientific output by the authors represented here.

Having decided what we wanted to include in our data, i.e. the EconLit-based publication records of Irish-based economists over the last thirty years, we went on to assemble the data. We began by entering a set of Irish affiliations into EconLit that we believed to be as comprehensive as possible. Our cutoff point was mid-2001. The institutions we considered were as follows: the Colleges of the National University of Ireland (Dublin, Cork, Galway and Maynooth), Trinity College Dublin, Dublin City University, the Economic and Social Research Institute, Central Bank of Ireland, Dublin Institute of Technology, Queens University Belfast, the Northern Ireland Economic Research Centre, the civil and public services of both jurisdictions, institutes of technology, and the University of Ulster. This produced lists of papers with the corresponding authors going back to the late 1960s. Once we had the authors, we re-entered their names to ensure a full list of their publications; if they had changed affiliation, even temporarily, a reliance on the affiliation-based list might understate peoples' records. In entering the names, we were careful to search for a number of forms of names. For example, someone called Patrick Murphy might have occasionally appeared as P. Murphy or Paddy Murphy. Using this process, we were able to generate what we consider to be a comprehensive list of EconLit cited articles published by economists working in Ireland. 1

It could be argued that a more reliable way of compiling the data would be to use staff lists from a base period (such as 2002) and assembling publication lists of those individuals. We considered this strategy but decided against it for the following reason. As we are attempting to look at the profession in Ireland over a thirty year period, an analysis of those currently working would not

1 The searches were filtered using the EconLit article type "Journal Article". This will almost totally exclude comments, replies and the like so that the focus is on journal articles proper. 
provide a comprehensive picture. In addition, by relying on the staff lists of Economics Departments or Business Departments, we would certainly miss people who publish in economics journals but who work in other departments such as Politics or Sociology.

Having assembled the information from EconLit, the issue arose of whether we should restrict our attention to articles cited in that index. We had particular concerns about journals like the Irish Banking Review, which was once cited in EconLit but is no longer cited. Similarly, the Journal of the Statistical and Social Inquiry Society of Ireland (JSSISI) is now cited but it was not cited for many years. The approach we adopted was to supplement the EconLit listing with articles from the Irish Banking Review, JSSISI and the Irish Journal of Agricultural Economics and Rural Sociology all of which have appeared in EconLit at some time. This is undertaken in order to provide as comprehensive as possible a list of authors and sources. To our knowledge this has not been undertaken for Irish economists previous to this work. Given that our objective is to provide a "benchmark", we decided that the EconLit "stamp of quality" was a reasonable touchstone.

As a final check on the accuracy of our data, we sent the entire list of names to the heads of the Economics Departments in the institutions named above. The heads were asked to go through the names (600 plus) to ensure that there were no omissions. In general, we are confident that the data are representative of the output, in journal format, of Irish-based economists.

\section{RESULTS}

We begin presenting the results of our analysis by explaining one element of the data records. In total we identified 659 individual authors. For every individual in the dataset we construct a record of his or her "hits" and "contributions". By "hit" we mean the appearance of their name as either authoring or co-authoring a paper. Hence, a person who had one singlyauthored paper and one co-authored with one other would have two "hits". By "contribution" we mean the proportion of a paper authored by an individual. In this case, the person just described would have 1.5 contributions, one for the singly-authored paper and a half for the co-authored paper. While hit can be considered a raw estimate of an individual's output, contribution adjusts for co-authorship. These individuals published 1,637.3 contributions and 2,178 hits over the period. We recognise that this may under-represent the relative complexity and quality of co-authored papers and that it also assumes equal intellectual ownership by individual co-authors. We are, however, constrained 
to this approach both by reference to existing literature (see for example Sauer (1988)) and by the nature of the data sources available.

\section{Journals}

In Table 1, we present the journals Ireland's economists have used as outlets over the last thirty years. We present these figures using our contribution records only, which seems more logical when talking about journals rather than individuals. The table contains a list of the top twentysix $^{2}$ journals (in terms of number of contributions) and provides a breakdown by decade, plus a total. It should be remembered that the 1990 s column actually includes papers up to Summer 2001.

The first point to be taken from the table is the huge expansion in the TOTAL number of contributions between the $1970 \mathrm{~s}$, the $1980 \mathrm{~s}$ and the $1990 \mathrm{~s}$. We recorded 217.8 contributions in the $1970 \mathrm{~s} ; 406.4$ in the $1980 \mathrm{~s}$; and $1,013.2$ in the 1990s. As we do not have precise information on the number of practicing economists in Ireland over this period, it is not possible to be definitive as to whether the increase over time is related to output per economist or an increase in the number of economists.

From our own experience and knowledge there has clearly been an increase in the number of economists employed in universities, the semi-state sector and consultancy firms. However, in the absence of a comprehensive database of practicing economists in Ireland we cannot make definite conclusions about the source of the increased output. The number of contributions grew by 4.4 times between the 1970 s and the 1990 s and by 2.4 times between the 1980s and the 1990s.

In addition to the increase in contributions, the other feature of the profession that is immediately apparent from the table is that Ireland's economists have been heavily reliant on Irish outlets for their work. Over the full period, there have been $1,609.5$ contributions - 793.6, or 49 per cent of these have been in three main Irish journals: The Economic and Social Review, the Irish Banking Review and the Journal of the Statistical and Social Inquiry Society of Ireland. If we look at this breakdown by the 1980s and the 1990 s, we do see a reduction in the proportion of papers in Irish outlets. In the 1970s 73 per cent of all articles by Irish economists appeared in these journals, falling steadily to 55 per cent in the 1980 s and 41 per cent in the 1990 s. The percentage in Irish journals would, however, be even higher if we included the Irish Journal of Agricultural Economics and Rural Sociology. While this does point to an increasing "internationalisation" of the profession in Ireland, the

2 These are the journals which published ten or more hits by Irish economists over the period 1970-2001. 


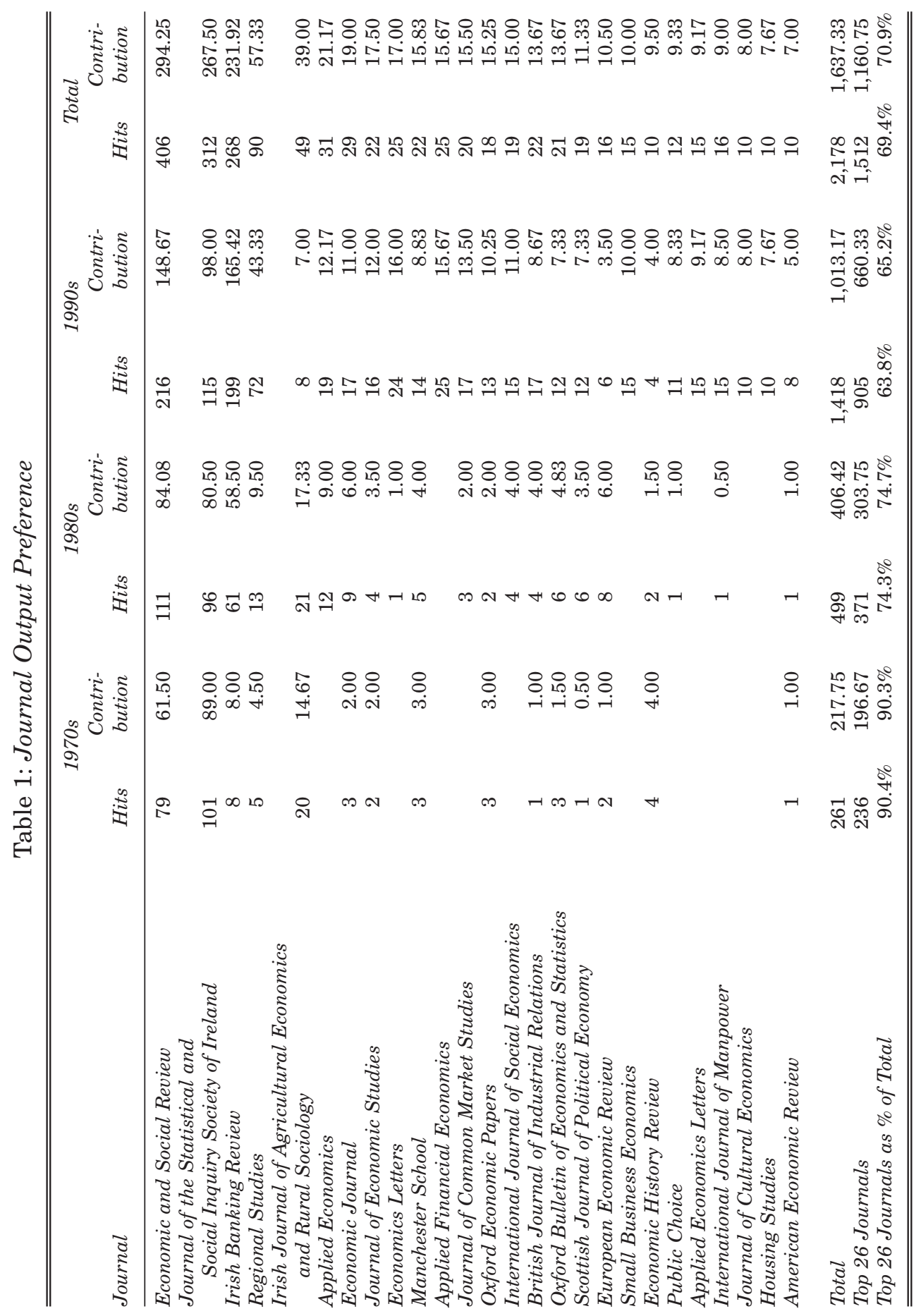


authors were somewhat surprised at the degree to which the domestic proportion remained high.

After the Irish journals, the most popular outlets for Ireland's economists have been Regional Studies (57.33 contributions); Applied Economics (21.17 contributions) and the Economic Journal (19 contributions). The prominence of Regional Studies, when combined with the reliance on the Irish outlets, may suggest a picture of Ireland's economists writing about Ireland in a national or regional context. The distribution of topics and research areas amongst Irish economists is one to which the authors intend to return in another paper.

\section{Journals and Quality}

There will always be disagreement about the relative quality of journals and so it is probably futile to make any comments on the overall quality of the main outlets for Ireland's economists based on Table 1. We leave it to the reader to make his or her own assessment of whether the picture derived from Table 1 is positive or not. In Table 2 and Table 3 we examine the extent to which Ireland's economists have been publishing in top quality journals. Our "top 5" are those used by Scott and Mitias (see above) - our "top 10" are those used by Kalaitzidakis et al. (again, see above). In both of these tables, and for later tables where we also look at individuals, we include both contributions and hits.

In Panel A, Table 2, we present those individuals who have published in the top five journals of the last thirty years. Overall, Ireland's economists have made 23.5 contributions to these journals, registering thirty-one hits, a shade under one hit in these top journals per annum. We will again leave it to the reader to make a subjective assessment of whether or not this is a good or bad performance. However, we will draw attention to two objective facts. First, the output is highly concentrated. Second, and this surprised the authors; there has been essentially no change in the absolute number of contributions or hits between the 1980s and the 1990s (10 contributions in the 1980 s versus 11 in the 1990s; twelve hits in the 1980s versus sixteen in the 1990s). Given that the number of contributions almost tripled between the $1980 \mathrm{~s}$ and the $1990 \mathrm{~s}$, this points to a possible relative decline in the quality of the output of Ireland's economists. While not wishing at this stage to make definite conclusions on the academic productivity of Irish economists, we note the similar study of Brazilian economists (Faria, 1998, op. cit.) which found that over the 19841999 period only nine contributions by these 506 economists were recorded in a top journal. Combes and Linnemer (2000) examine French academic economists' output in EconLit journals since 1969 and find that the 1,540 researchers in their database published 150 articles in the top five journals as per our rankings above. 
Table 2: Irish Authors Publishing in Top Journals

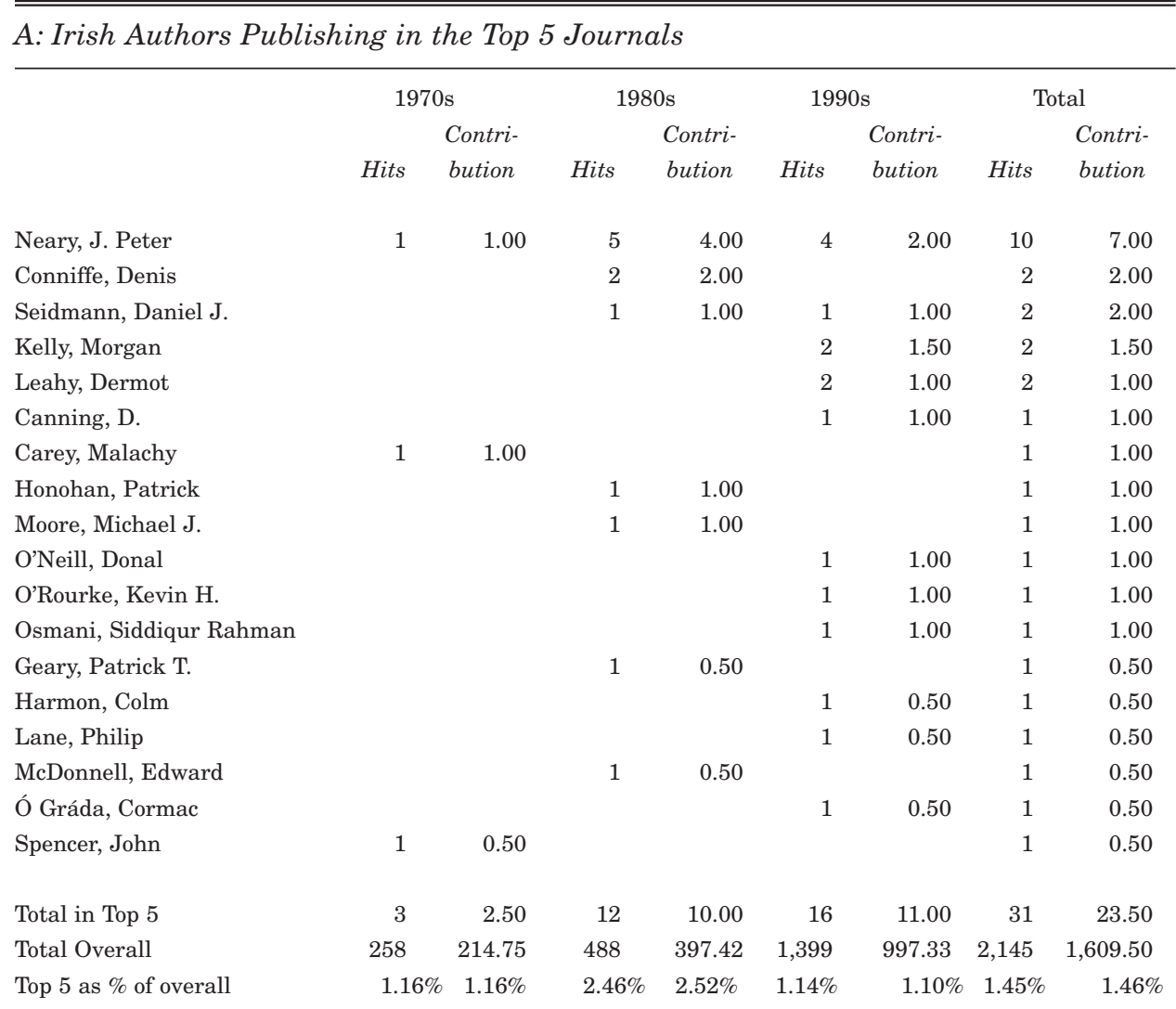

B: Irish Authors Publishing in the Top 10 Journals

\begin{tabular}{|c|c|c|c|c|c|c|c|c|}
\hline & $\begin{array}{r}19 \\
\text { Hits }\end{array}$ & $\begin{array}{l}\text { Os } \\
\text { Contri- } \\
\text { bution }\end{array}$ & Hits & $\begin{array}{l}\text { Contri- } \\
\text { bution }\end{array}$ & 19 & $\begin{array}{l}\text { Contri- } \\
\text { bution }\end{array}$ & Hits & $\begin{array}{l}\text { tal } \\
\text { Contri- } \\
\text { bution }\end{array}$ \\
\hline Neary, J. Peter & 2.00 & 2 & 8.00 & 6 & 5.00 & 3 & 10 & 15 \\
\hline Seidmann, Daniel J. & & & 3.00 & 3 & 2.00 & 2 & 5 & 5 \\
\hline Canning, D. & & & 1.00 & 1 & 3.00 & 3 & 4 & 4 \\
\hline Kelly, Morgan & & & & & 4.00 & 4 & 4 & 4 \\
\hline Conniffe, Denis & & & 3.00 & 3 & & & 3 & 3 \\
\hline Honohan, Patrick & & & 2.00 & 2 & 1.00 & 1 & 3 & 3 \\
\hline Browne, F. X. & & & 2.00 & 2 & & & 2 & 2 \\
\hline Leahy, Dermot & & & & & 4.00 & 2 & 2 & 4 \\
\hline O'Rourke, Kevin H. & & & & & 2.00 & 2 & 2 & 2 \\
\hline Borooah, Vani K. & & & 3.00 & 2 & & & 2 & 3 \\
\hline Bradley, John & & & 1.00 & 1 & 2.00 & 1 & 2 & 3 \\
\hline
\end{tabular}


Table 2: Irish Authors Publishing In Top Journals (contd.)

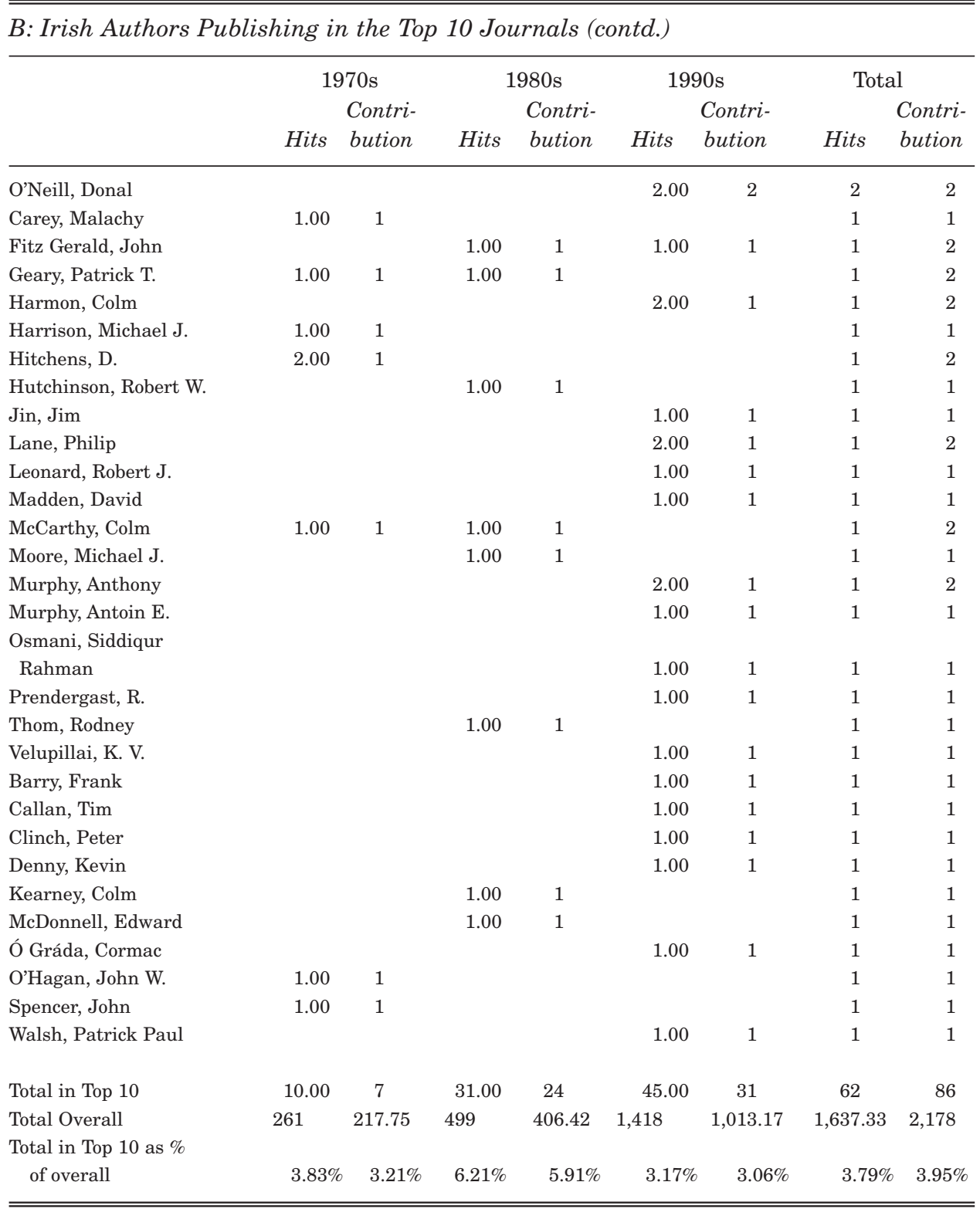

It is of course important to note that the probability of publishing in the top journals is a function of a number of factors; among these are the quality of a paper, the space available in the journal (which will influence the acceptance rate), the degree of competitive pressure as measured by the 
numbers of those active in the area, and the number of papers a person prepares for a journal. The relative decline in Irish economists' contributions to the top journals may reflect a decline in one or more of the above. In terms of space, we note that the $A E R$ in 1970 published 1,064 pages, 1,070 in 1980, 1,228 in 1990 and 1,536 in 2000; Econometrica changed pages from 952 to 1,623 to 1,496 to 1,548 ; JPE page count went, over the same period, from 1,390 to 1,287 to 1,354 to 1,376 ; $Q J E$ ranged from 715 through 787, 1,077 and 1,478, while the $E J$ page count went from 1,078 through 1,014 and 1,459 to 1,013. Clearly, therefore, there has not been a decline in the space available in these top journals.

An alternative approach might be to consider whether or not there has been an increase in the competition for space, as measured by the numbers of active economists seeking to publish. Ellison (2000; section 6) provides some data pertinent to this. He notes for top journals that measures of the number of active authors has not increased. He also notes that the membership of the American Economic Association has risen only marginally over the 1970-1998 period, from 18,908 to 20,874 , a rise of just over 10 per cent. He also notes that $A E R$ submissions dropped from 1970-1980, grew somewhat to 1990 and have remained essentially static since then. Submissions to Econometrica grew substantially to the mid 1980 s and have remained static since. Thus, we can conclude that whatever the cause in the relative decline it is not immediately attributable to increased competition.

In Panel B, Table 2 we consider those economists publishing in the top ten journals; essentially similar points emerge as did from Panel A. Over the thirty-year period, there were sixty-two contributions, which is two per year for the entire profession. As before, this may be good or bad - we leave it to the reader to decide. Between the $1980 \mathrm{~s}$ and the $1990 \mathrm{~s}$, the number of contributions rose only slightly. Therefore, there was a relative decline in the proportion of papers going to the better journals. As to concentration of the output, of the sixty-two contributions, four authors (Neary, Seidmann, Kelly and Canning) account for twenty-two (36 per cent). When one remembers that Seidmann is no longer working in Ireland, the degree of concentration is even more apparent.

Shown in Table 3 is the annual output of Irish-based economists in these top ten journals. While there is no year since 1975 in which there has been no presence by Irish-based economists in the top ten journals, some facts are evident. First, there is heavy reliance on the $E J$ and $E E R$ as high calibre publishing outlets with over half of all articles appearing in these journals. Second, there are a number of years in which only one or two Irish-based authors break into the top journals. Third, there is no journal where there is a presence by Irish-based authors each year. 


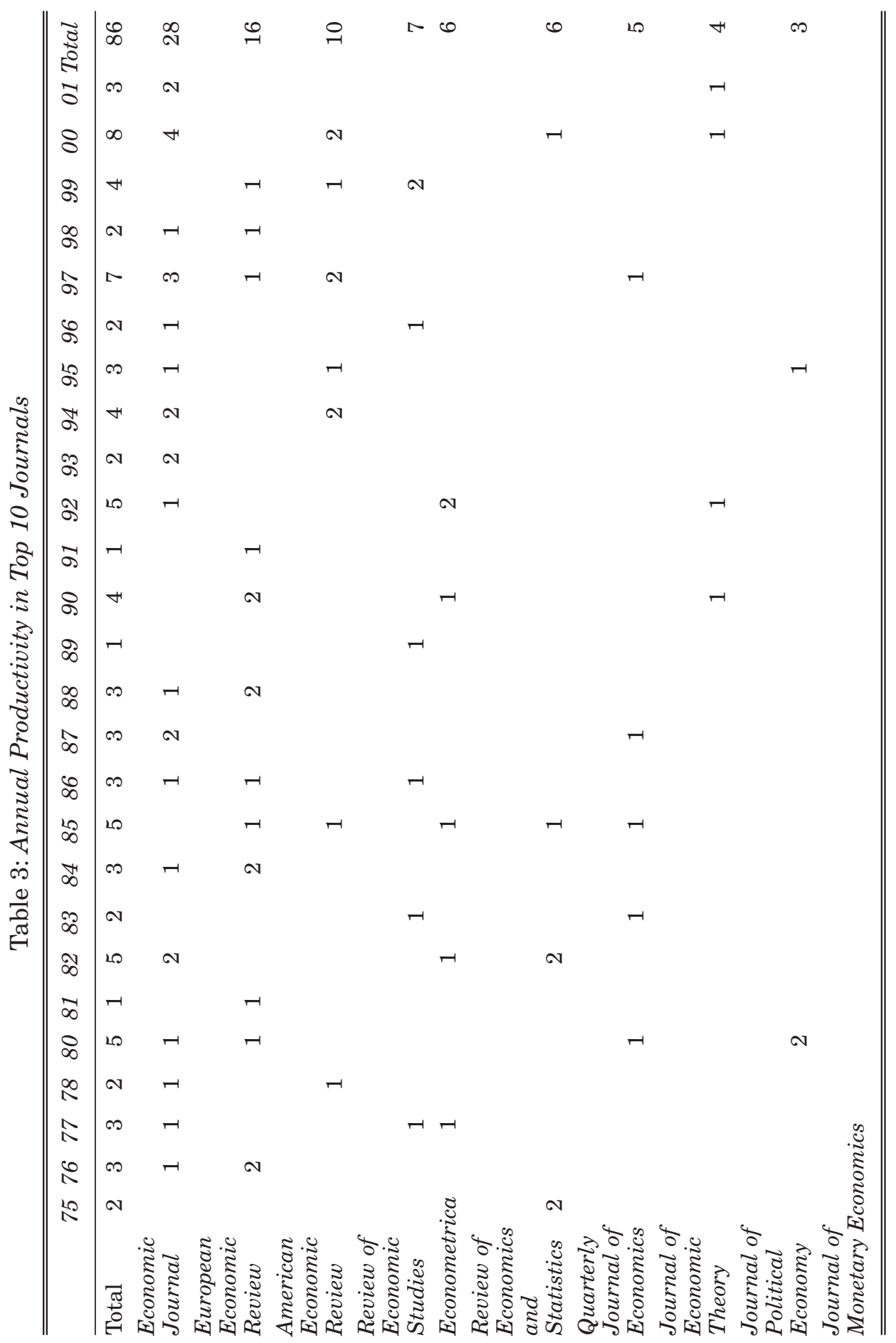




\section{Individuals}

The analysis so far has looked at the top quality output. At this point, we want to broaden the discussion and to look at the profession in Ireland across the full range of publication outlets. In Table 4, we look at the output of the leading publishers over the last thirty years. In this table, we record the number of contributions and hits for each economist as derived from EconLit, supplemented with IBR, JSSIS and IJAERS papers as discussed above.

Including only those economists with at least five hits in EconLit led us to arrive at a total of 104 . In Table 4, the authors are listed according to total hits over the 1970-2001 period and each cell contains the number of hits/ contributions in the corresponding period. Table 6 reproduces the same listing of names as Table 4 but with a ranking replacing the number of hits/ contributions in each cell. Hence, these two tables can be considered jointly.

The first issue we want to address as we move from the high quality tables to the broader tables is whether the "high-quality" producers are also the most prolific. At this point we will focus on hits as opposed to contributions in the discussion, although both indicators of output are included in the tables. If we look at the top twenty names in Table 4, we find that fourteen of these economists are also found among those who have published in the top ten journals. With two-thirds of the most prolific also featuring in the "top ten journal" list, this suggests a broad overlap between the two groups. We interpret this to mean that the most prolific economists are not generally adopting a strategy of many, possibly lower quality articles.

Eight of the top ten economists in Table 4 have been publishing since the 1970s and so the question arises as to whether their ranking is more related to longevity than productivity. We can illuminate this issue somewhat by comparing the rankings over the thirty-year period with the ranking for the 1990s. We can do this most readily by drawing on Table 6. Of the top ten over the thirty-year period, six were in the top ten in the 1990s, eight were in the top twenty and all were in the top thirty. This points to productivity as opposed to longevity being the reason for the top 10 being where they are.

In terms of institutional, and regional affiliation, we note from the tables that of the top twenty-two economists, three, Borooah, Hitchens and McKillop, are readily associated with Northern Ireland based institutions. The remaining nineteen are all predominantly associated with the Republic of Ireland. Although not by any means a completely accurate reflection of careers, it is interesting to note that of these nineteen, three (Nolan, Conniffe and Bradley) have spent considerable time at the ESRI with two others, Honohan and Kearney, also having held Research Professorships there in the recent past. Of the sixteen remaining non-ESRI/non-NI economists, two (Boyle and Geary) are Maynooth based, one Central Bank (Browne), one World Bank 


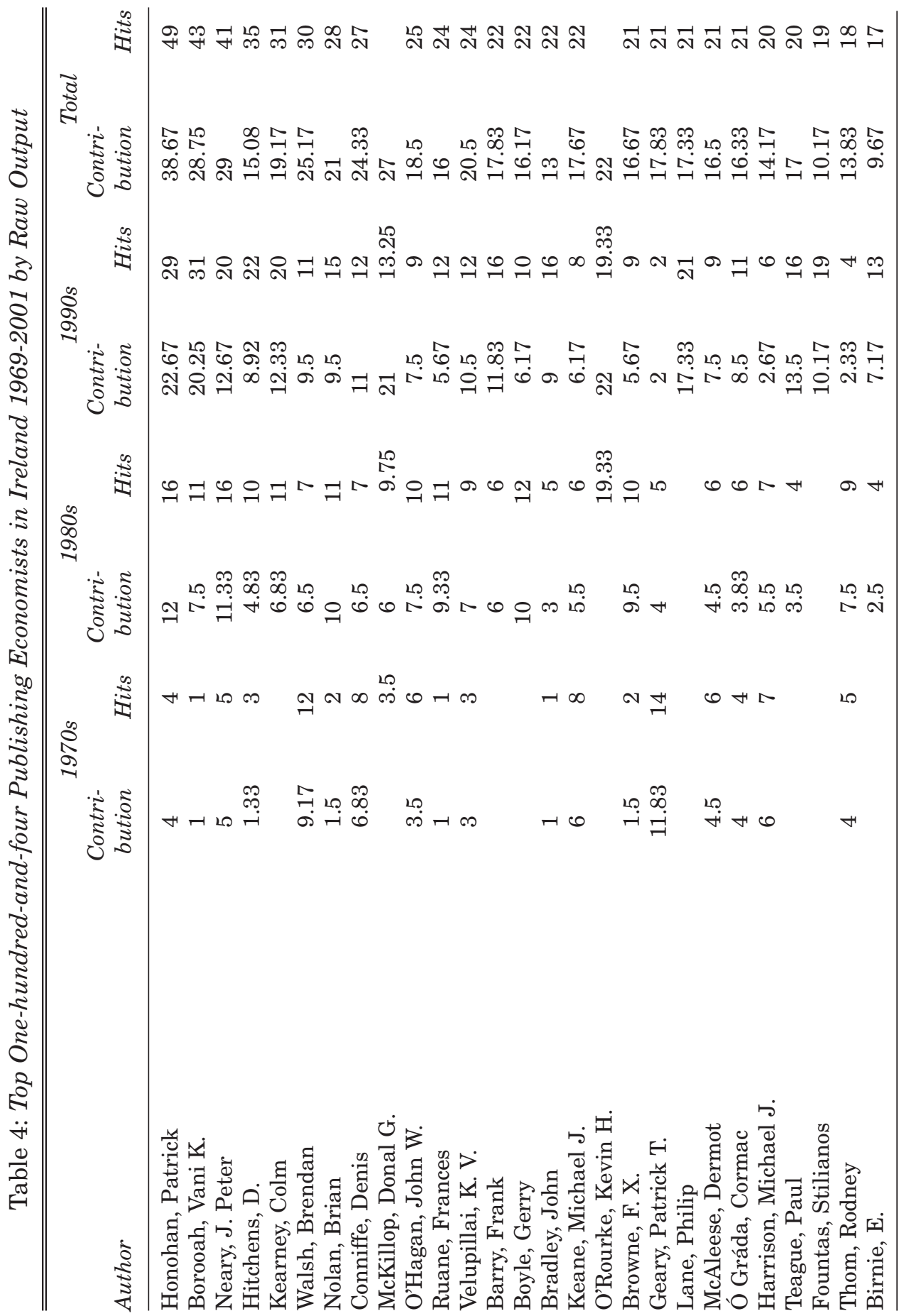




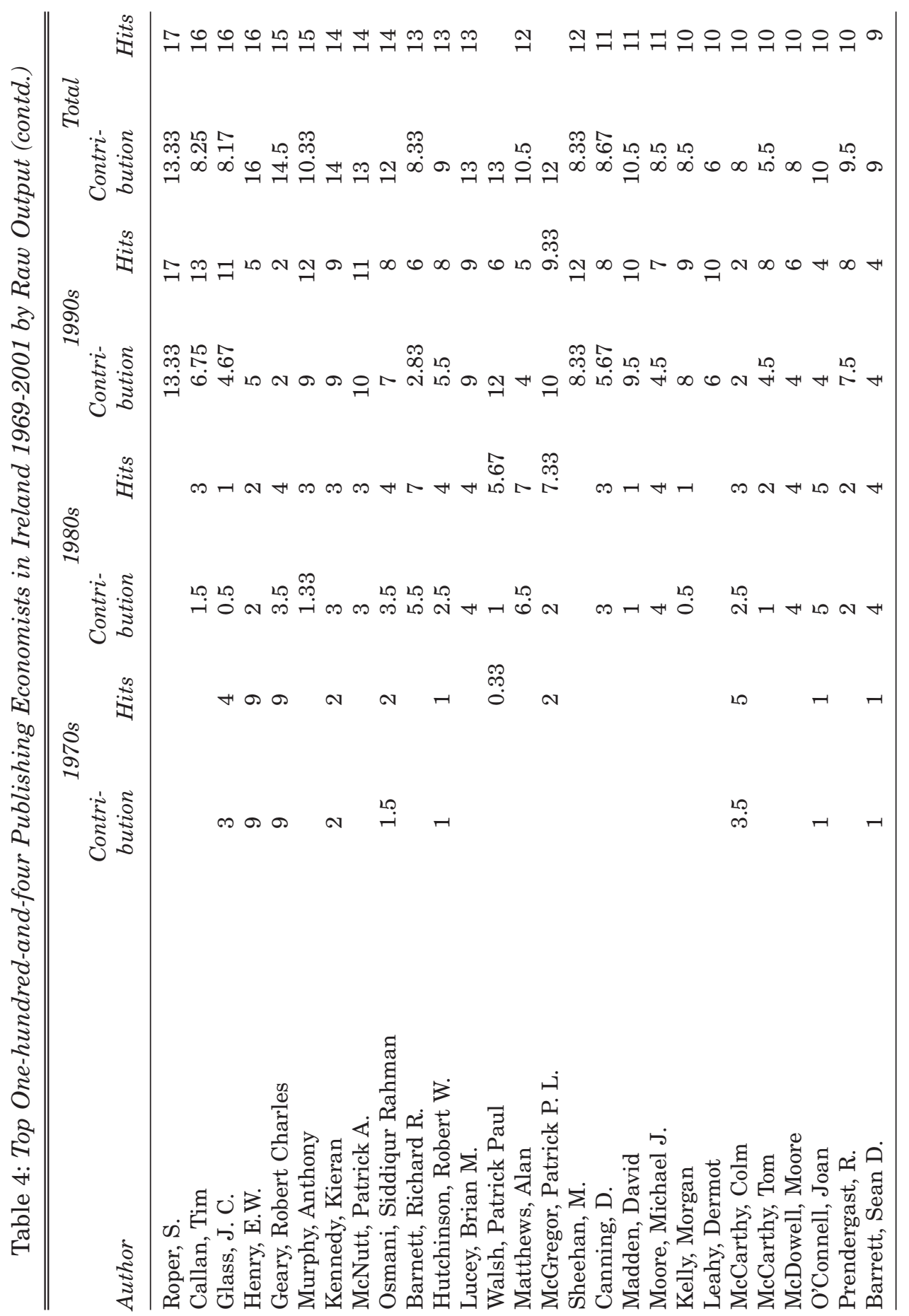




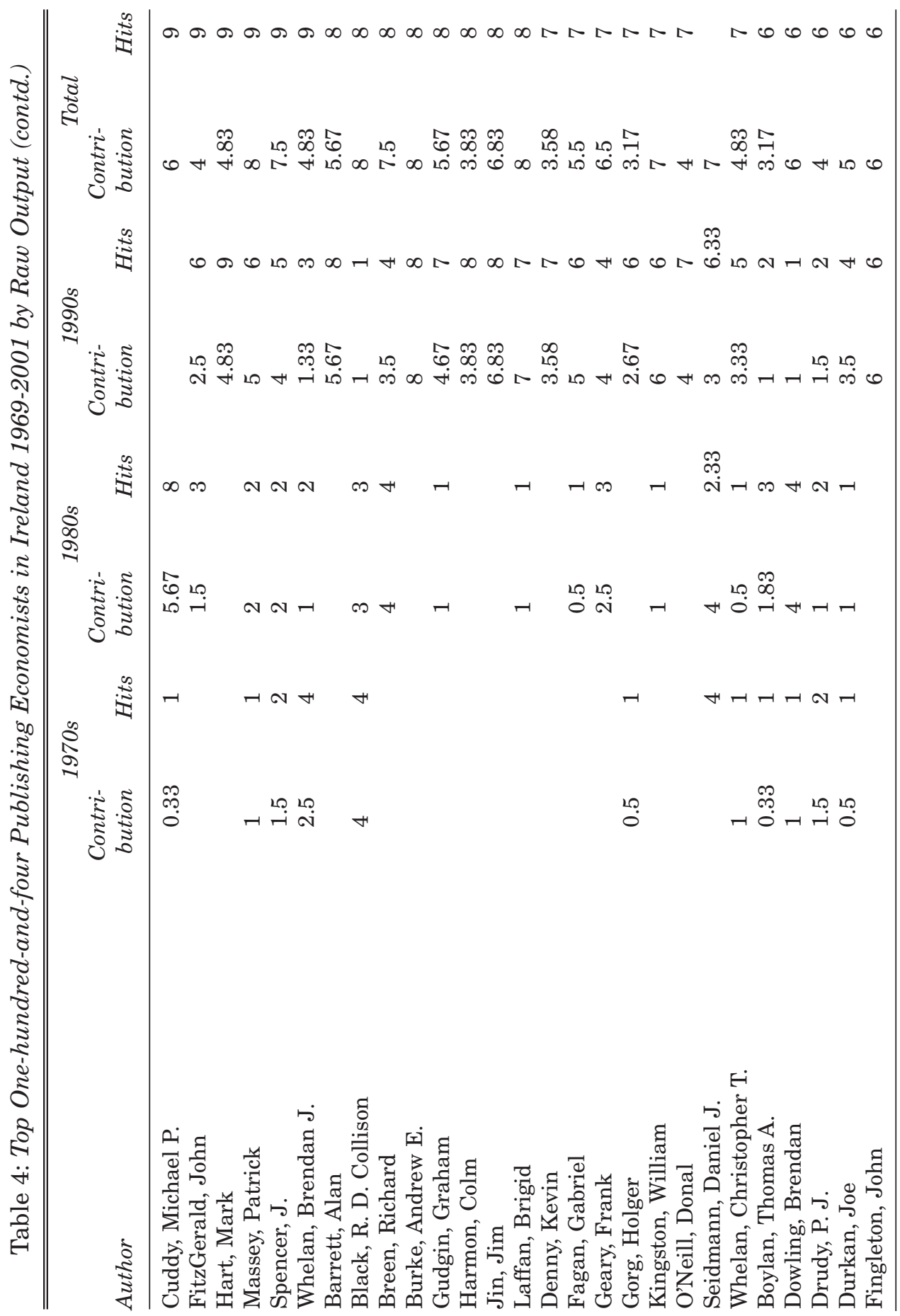




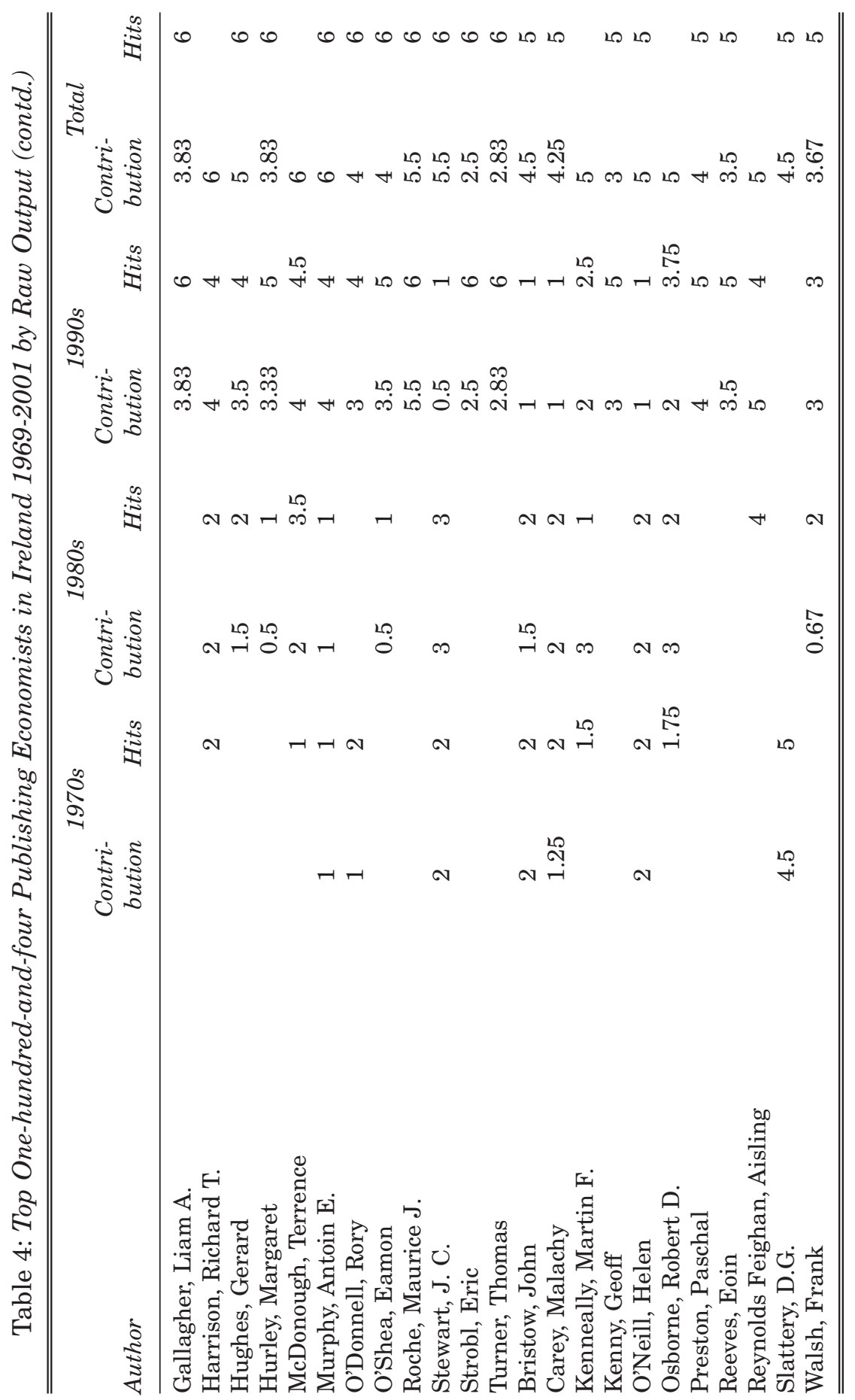


(Honohan), two Galway (Keane and Velupillai), four UCD (Neary, Walsh, Barry and Ó Gráda) and six TCD (Kearney, O’Hagan, Ruane, O’Rourke, Lane, and McAleeese). These results would on the face of it appear to be somewhat in conflict with those of Kalaitzidakis et al., who had placed Maynooth and then UCD as the highest ranked Irish economics departments. A partial explanation for this may be the focus of Kalaitzidakis et al. on top ten journals and the broader coverage here. We note, however, that if we examine Panel B, Table 2 and focus on the nine authors with three or more hits in the top 10 journals, none have a Maynooth affiliation and only one was associated with Trinity. All of these observations on departmental rankings take no account of possible differences in age profiles across departments. Such differences, plus other timing issues, would likely have impacts of ranking outcomes. ${ }^{3}$

Before leaving Table 4, we want to briefly address two other issues. First, we noted that there was a concentration of output among a small number of economists. At the very top of Table 4 we again see a degree of concentration among the top three economists - Honohan, Borooah and Neary. All have over forty hits or more, which is substantially above the next placed economists Hitchens, at thirty-five and then Kearney on thirty-one. Thereafter, the distribution declines at a more moderate pace.

Another point to be made is that all of the top ten economists are full professors, associate professors or ESRI research professors. This would seem to imply that the most prolific publishers have generally been rewarded in promotions. We note, however, that there are other authors in our database who are also in similar academic positions but who have not as many hits/contributions. This demonstrates that although a high rate of journal publication is a useful tool for obtaining a chair in the Irish system, it is neither a necessary nor sufficient condition for such promotion. Contributions in other areas to the academy via other forms of publication or through exemplary teaching or service may also be rewardable.

The data presented in Table 4 and Table 6 suffer from the flaw that a simple addition of hits or contributions in journals of very different quality is like adding apples and oranges. In order to overcome this (perfectly valid) criticism, we have adjusted the data using journal citation impact factors (JCIF) as supplied by ISI. 4 These factors provide a continuous measure of relative journal quality by taking account of the extent to which articles in the journals are subsequently cited. Some of the journals that show up in Table 4

3 We are grateful to the Editor for pointing this out.

4 The Journal Citation Impact Factors are published annually by Institute for Scientific Information, the publishers of the Science/Social Science Citation Index. Full details are available on their website at http://www.isinet.com/isi/ 
and Table 6 have not been given an impact factor and so disappear. It will often be the case that such disappearance represents a very infrequently cited journal and so this does not hinder our effort to get a continuous measure of quality. However, the JCIF is not by any means a complete or even less a unanimously accepted indicator of quality of a journal. A valid criticism that can be laid at this analysis is that we have used only one JCIF, the 1999 factor, rather than using the JCIF for each year. This is true, but the authors can only plead pressure of time and data collection. A fuller analysis would not only include this but would also include an adjustment for impact half-life. However, that remains a task for future research. In Table 5 we present the number of hits and contributions adjusted for the JCIF - in Table 7 we present the associated rankings.

The most interesting issue to consider as we adjust for quality of output is the degree to which the rankings change. In Table 8 we focus on the top 10 economists based on raw hits and JCIF-adjusted hits. What is striking about the first and third columns in this table is the degree of overlap among these top economists. As we noted earlier, the evidence there suggested that those economists with the most contributions generally were also well represented among those publishing in the top quality journals. This is repeated here where we see that the top ten when we look at raw counts are well represented in the JCIF-adjusted hit count. The biggest position change is Hitchens, who moves from a raw ranking of 4 to a JCIF adjusted rank of 45 , followed by Kearney who moves down 15 places from column 1 to 3 - however, he remains in the top twenty. The next biggest change is for Harrison - his move from number 21 in the raw hits count to number 8 in the JCIF-adjusted counts suggests a high average quality of output. Overall, the rank correlation for authors between contributions with and without JCIF impact factor adjustments is 57.9 per cent, while for hits it rises to 80.1 per cent. The degree of congruence is high, again showing that those who publish most tend also to publish in high quality journals as measured by their JCIF impact factor.

Returning to Table 7 we should point out a potential embarrassment to the economics profession in Ireland. Based on the JCIF-adjusted hit count, three of the top forty are not immediately classifiable as economists. Laffan ranks 34th, Breen ranks 38th, as does C. Whelan. As these are political scientists (Laffan) and sociologists (Breen and Whelan), their outperforming of so many economists is noteworthy. In addition, R C Geary ranks 12th overall, despite having died in the mid-1980s. 


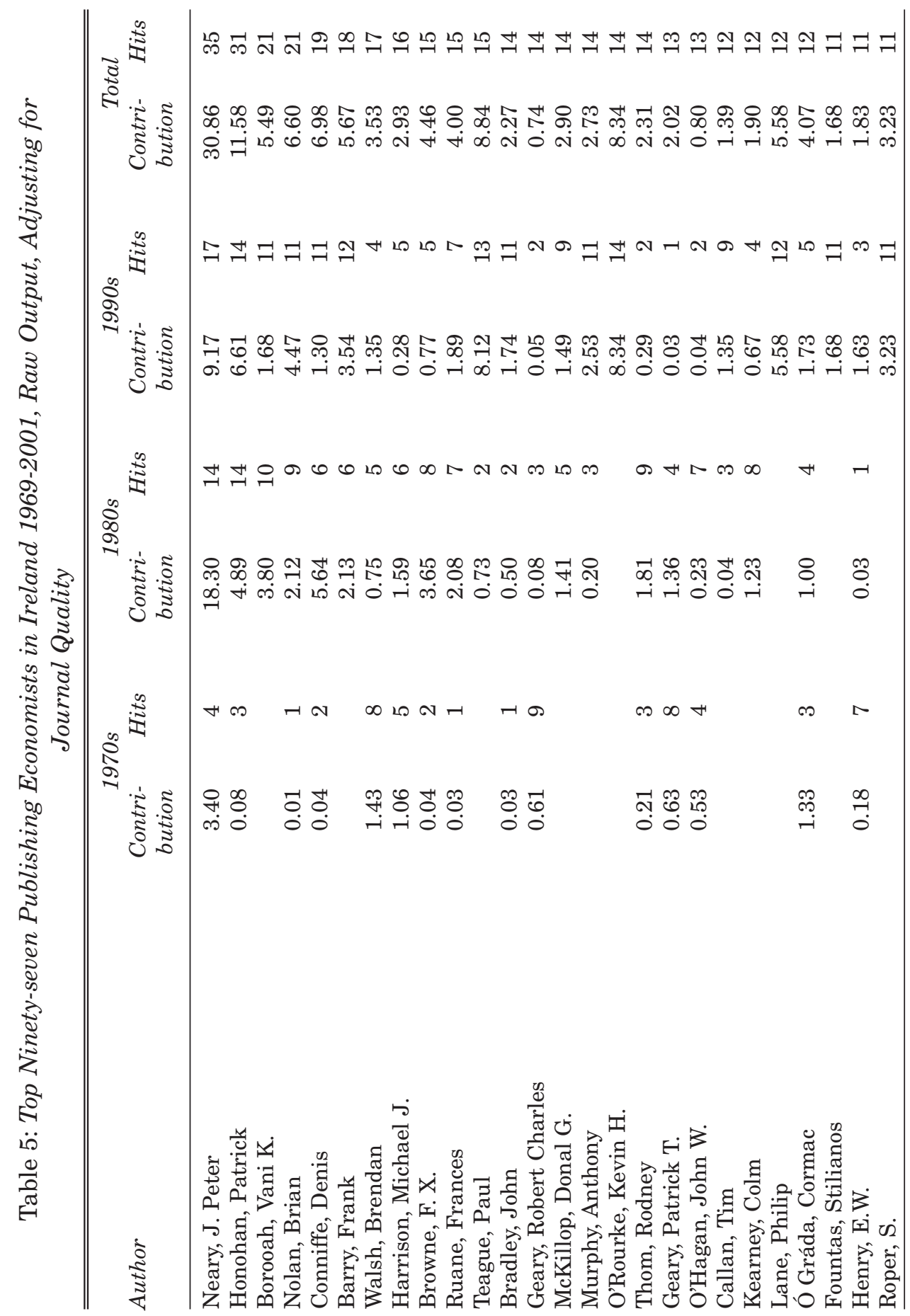




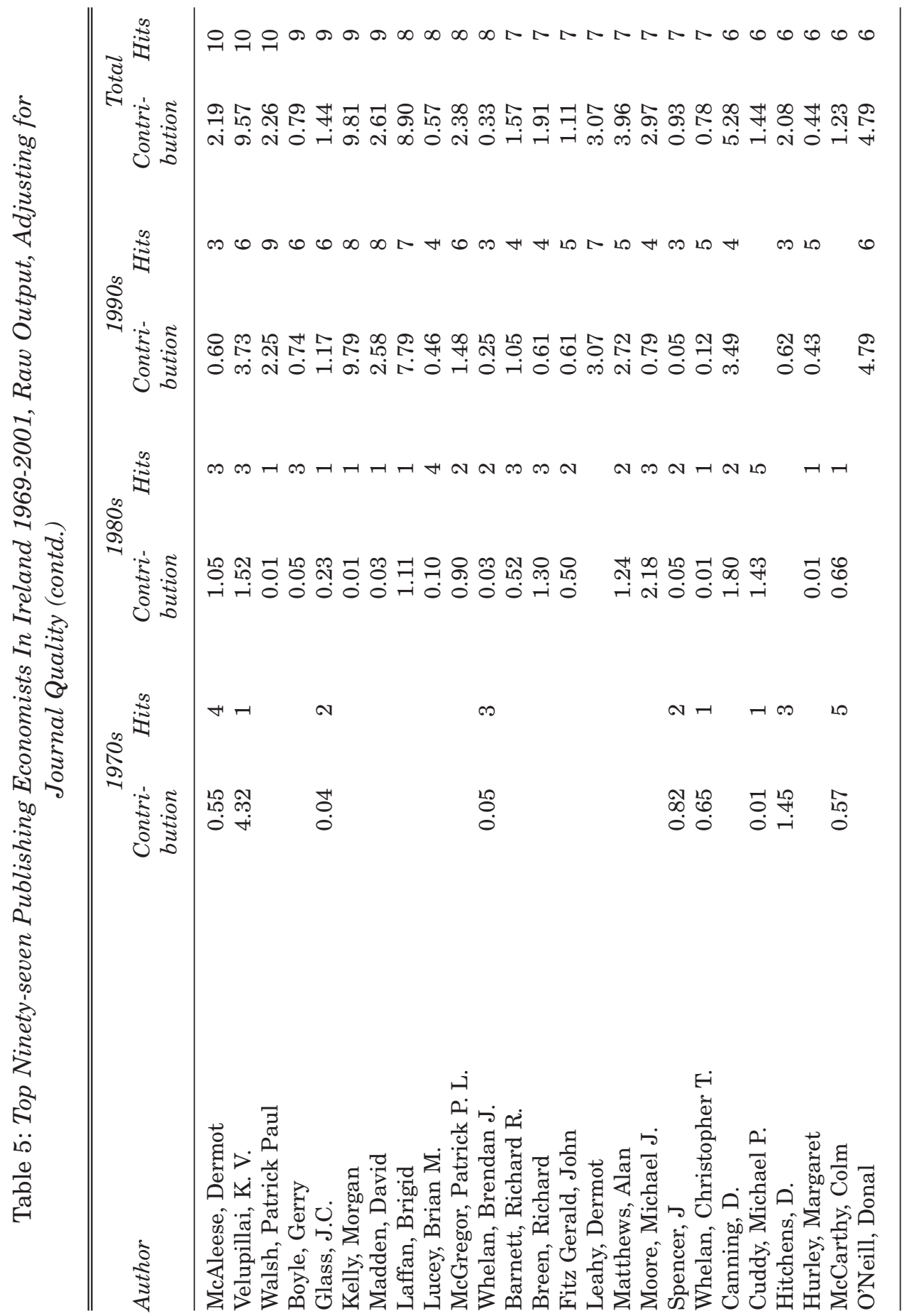




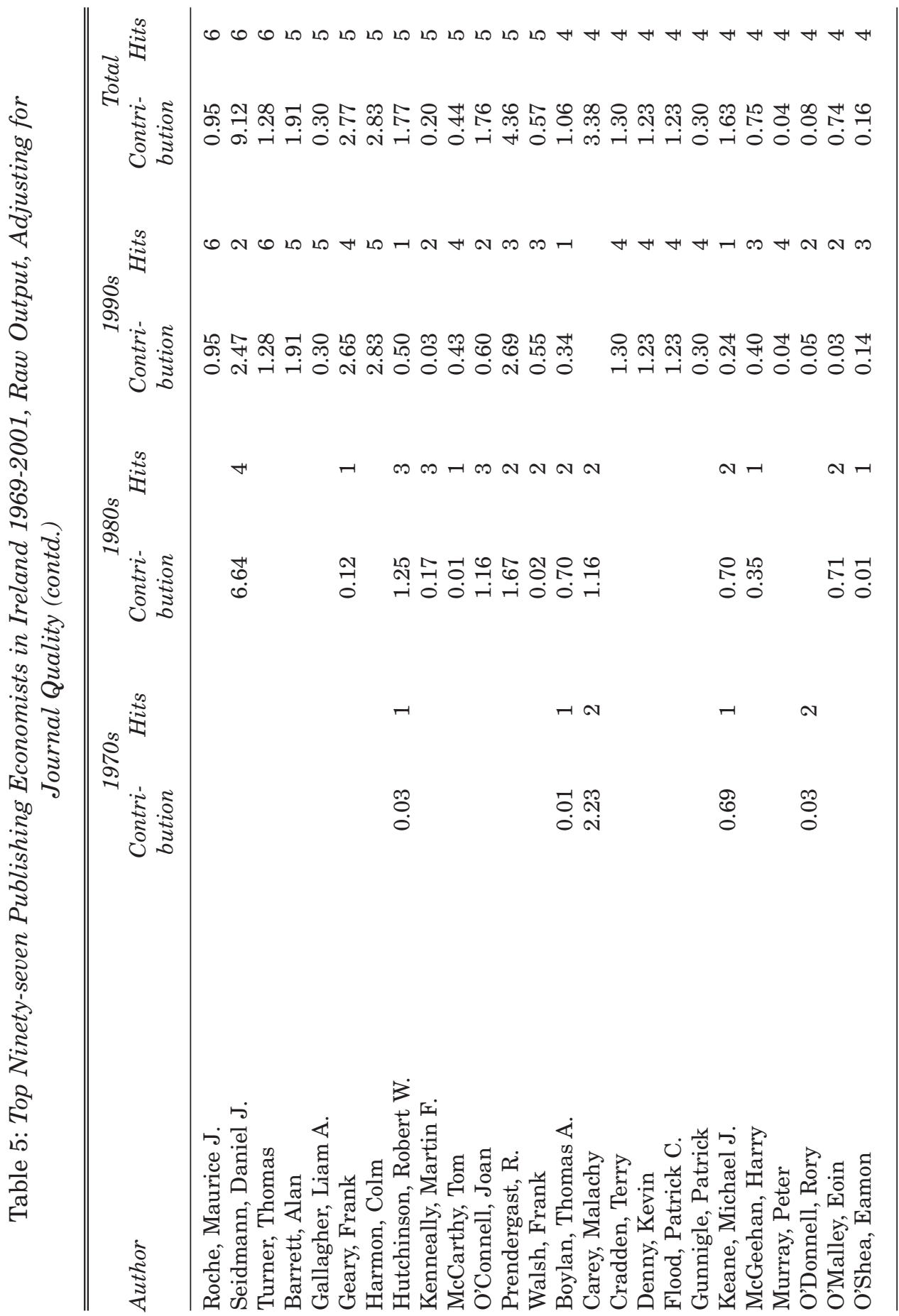




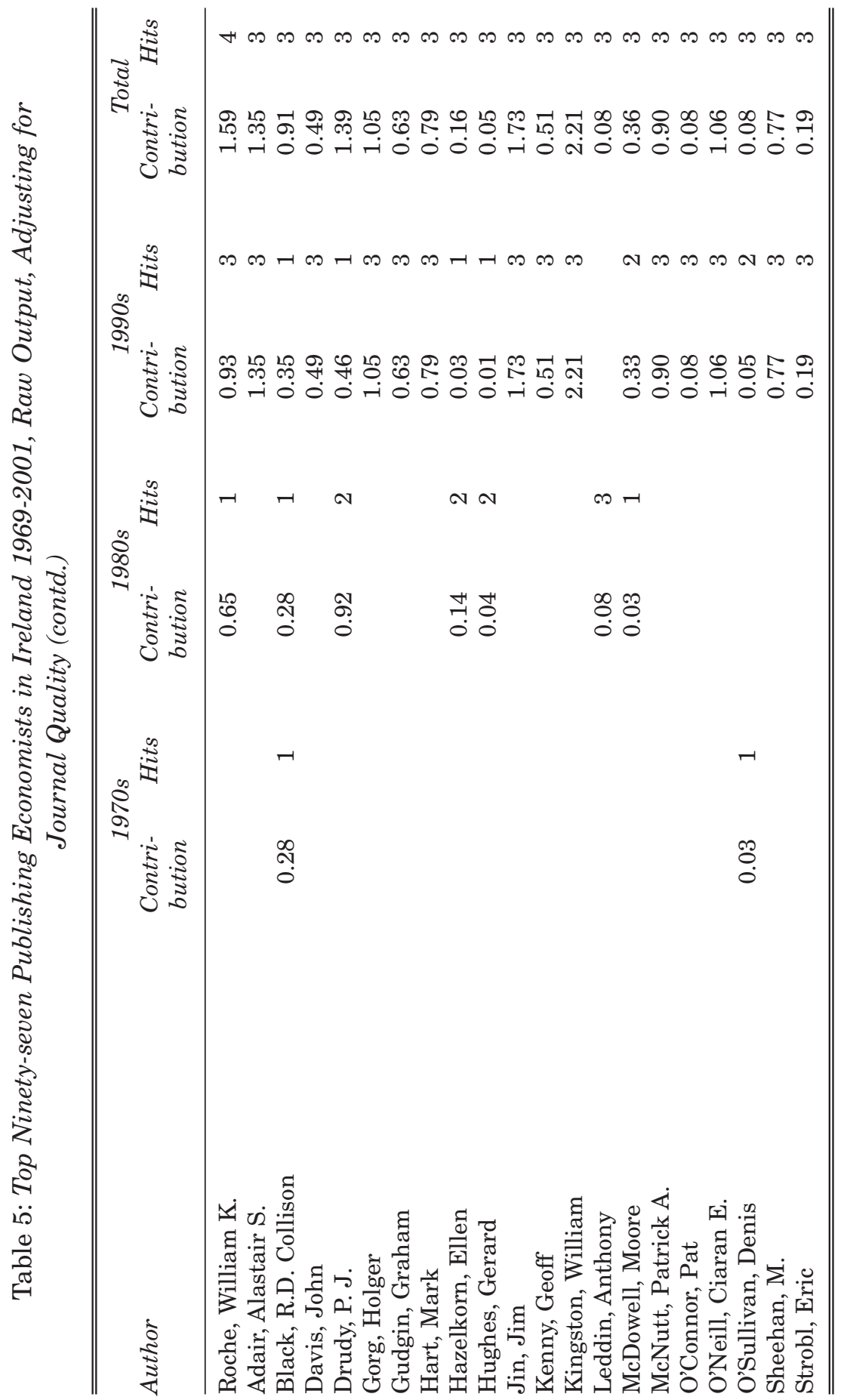




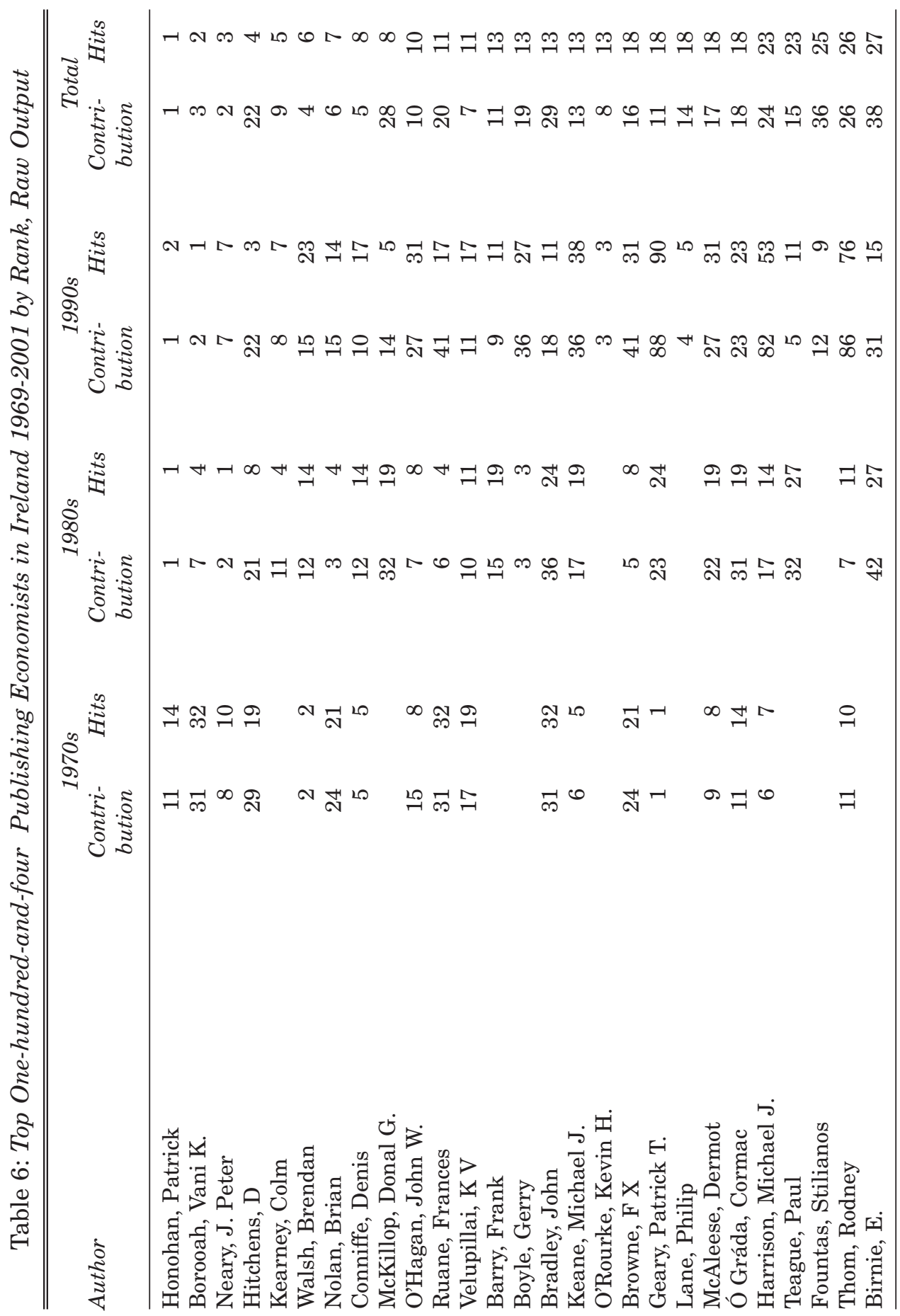




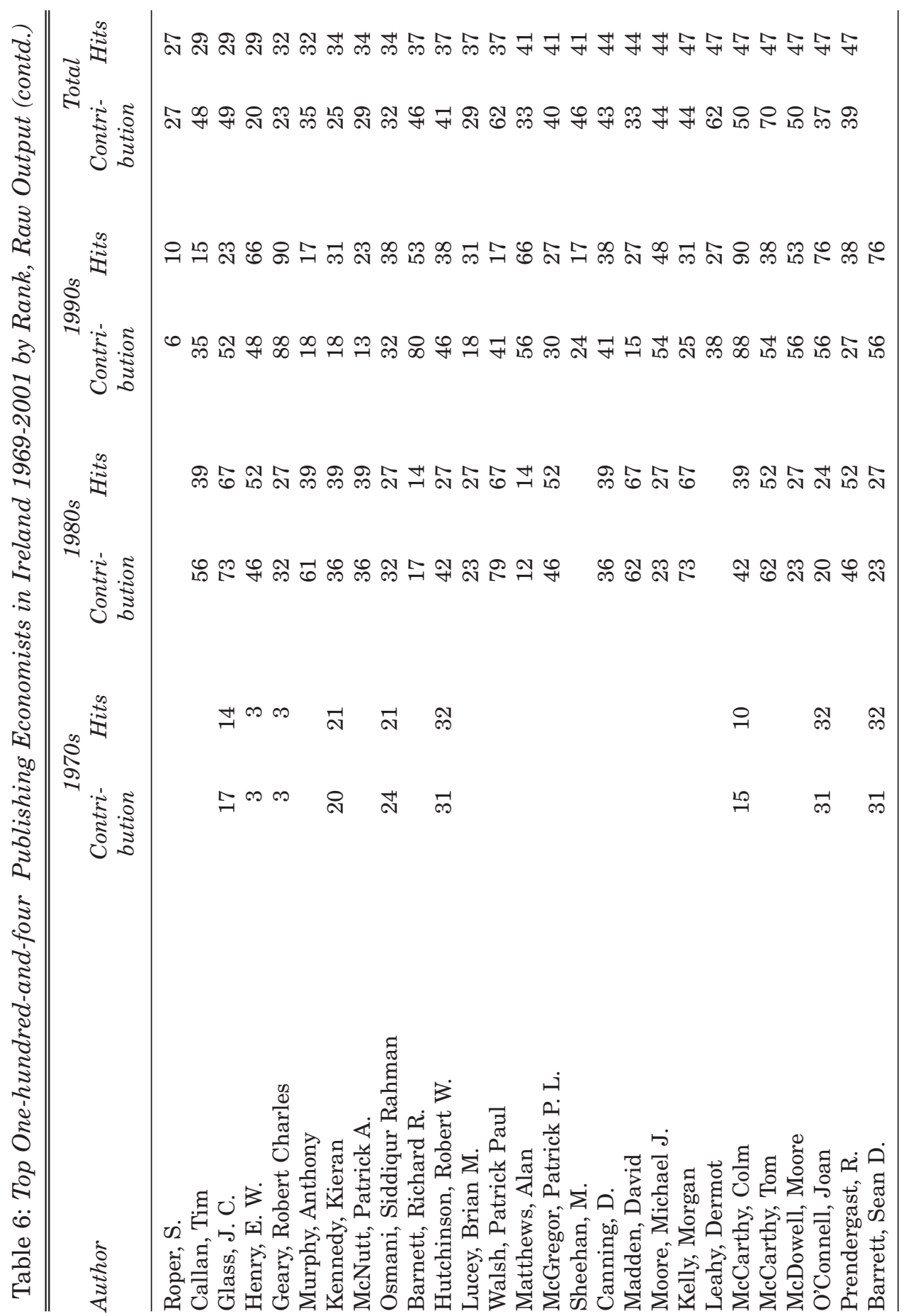




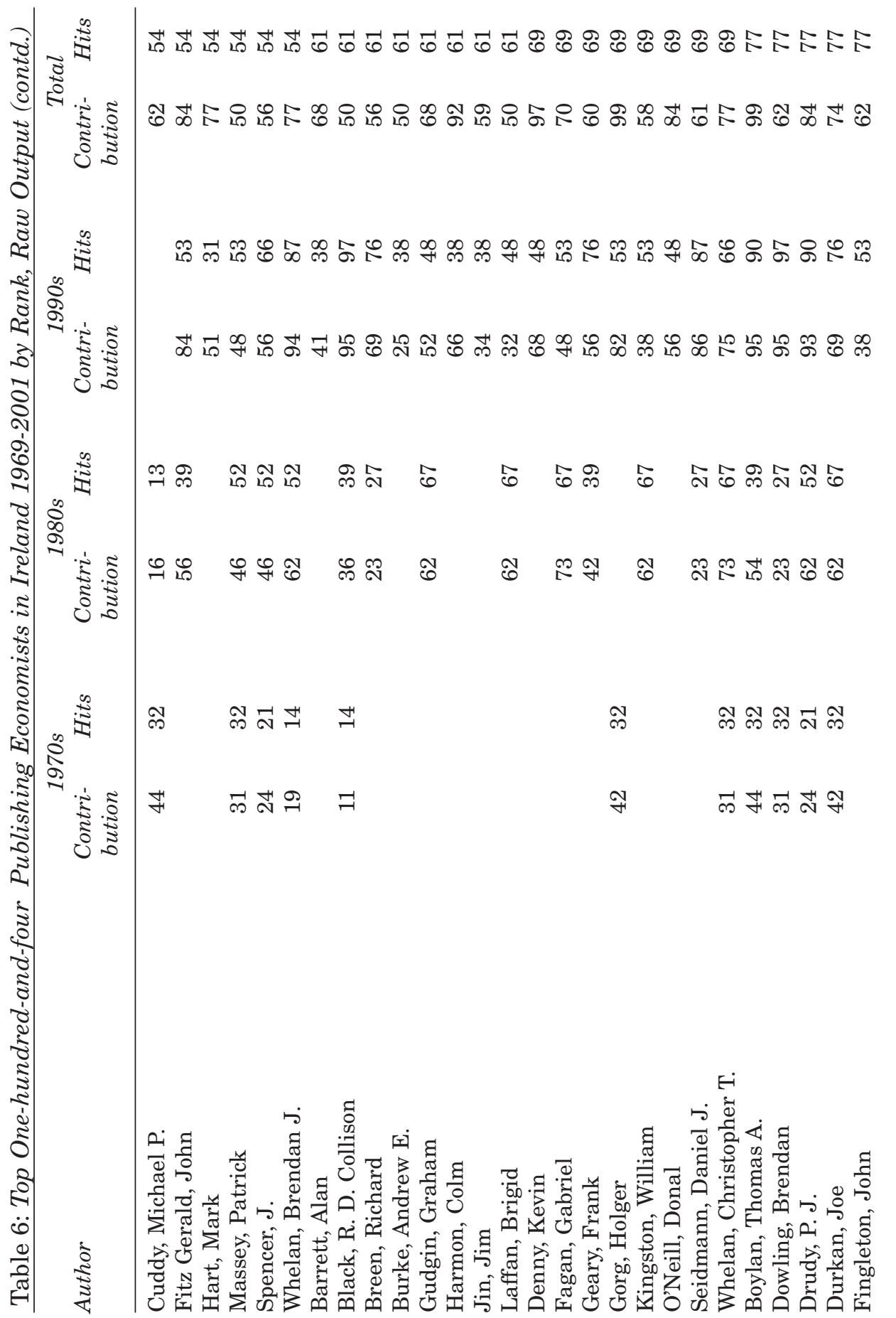




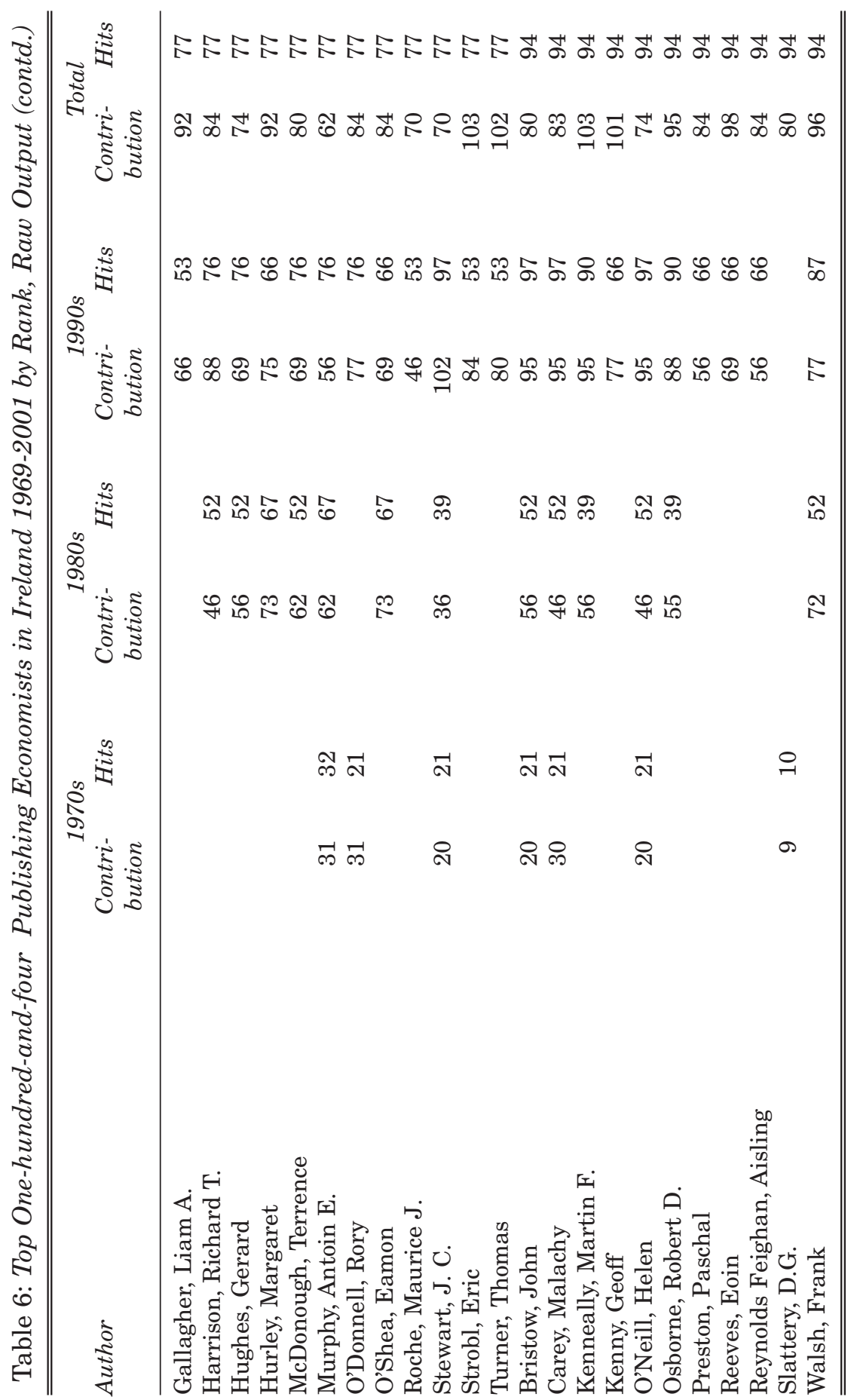




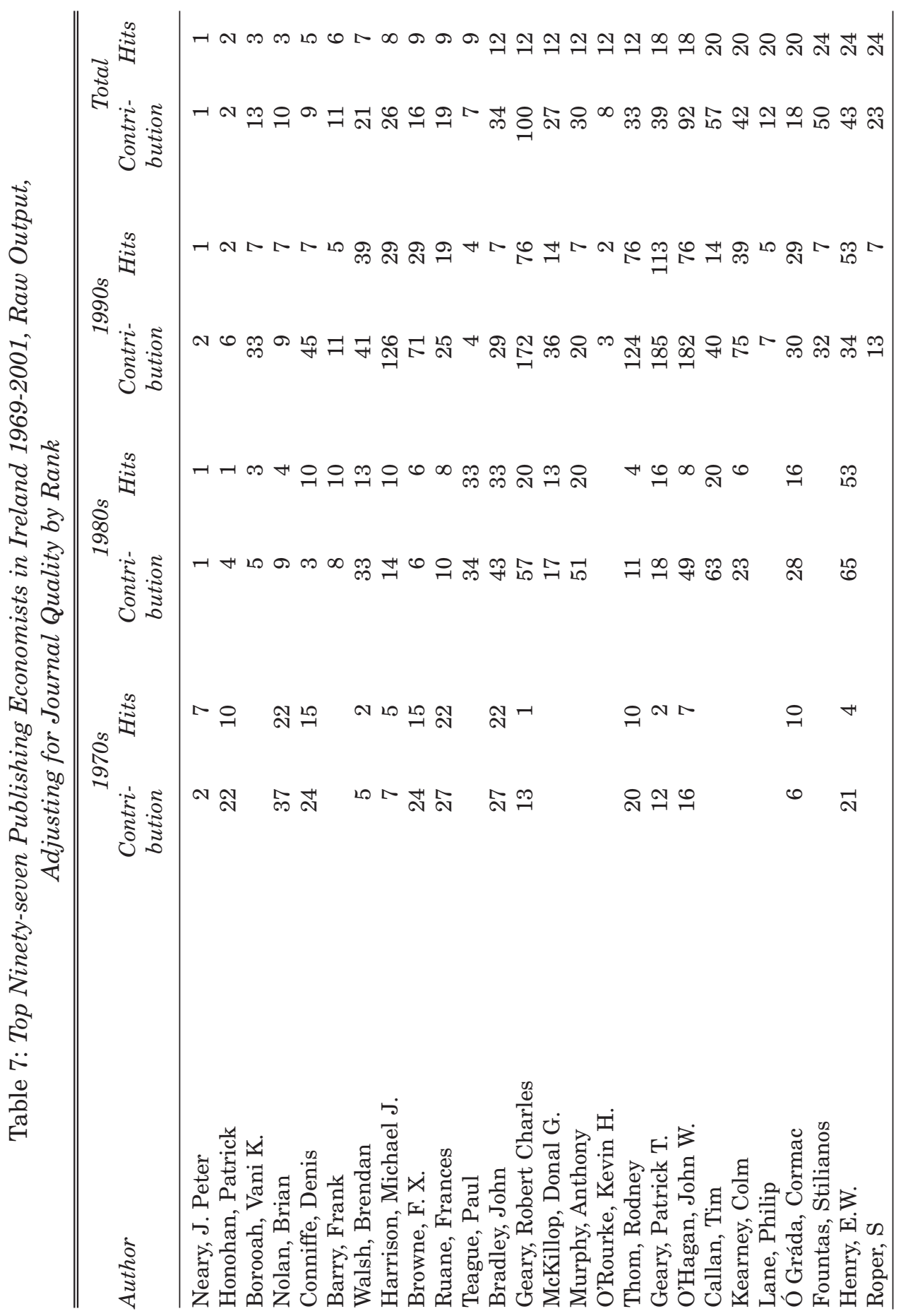




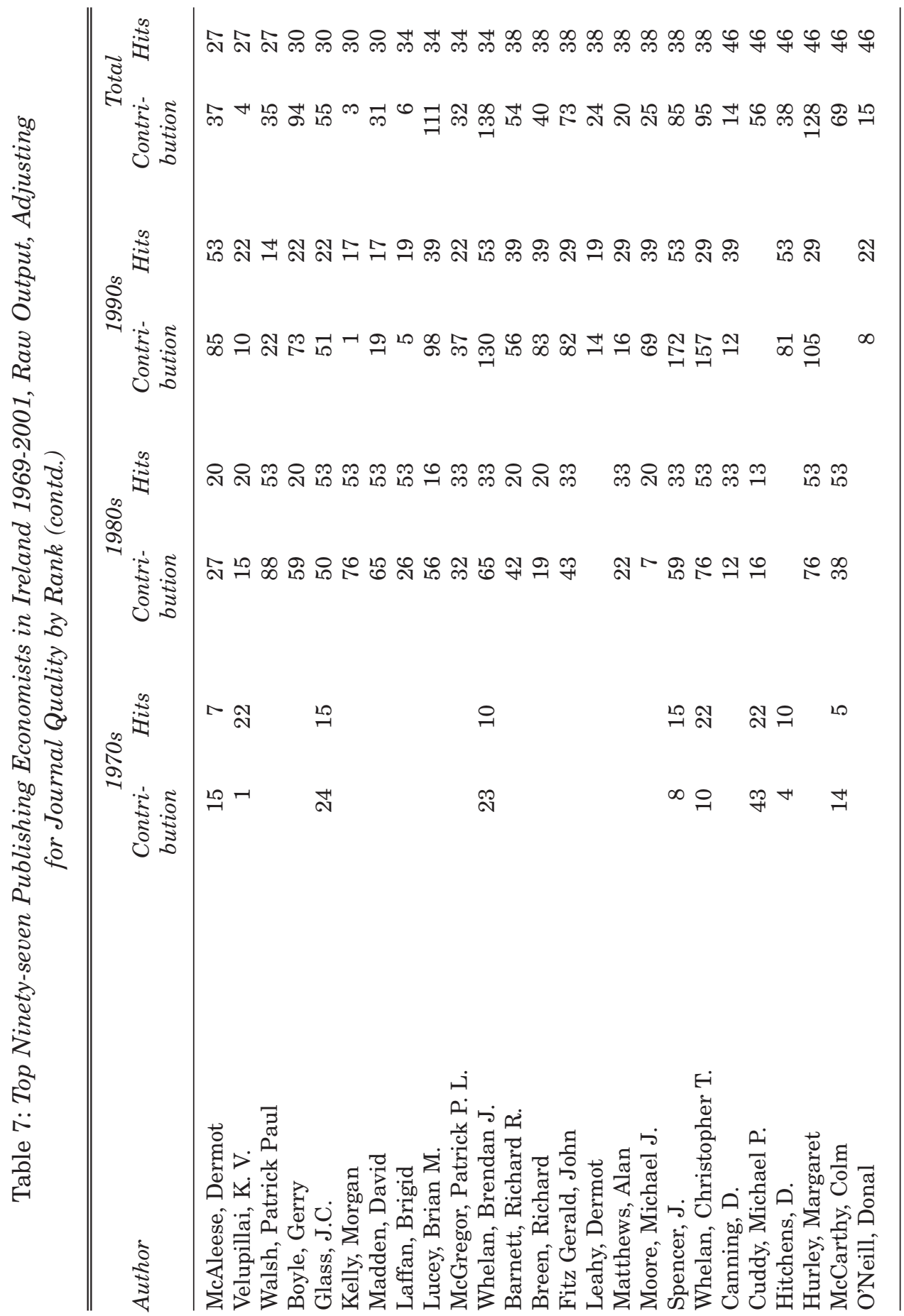




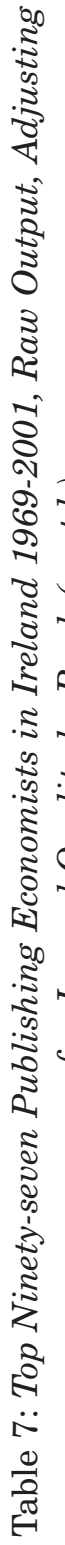

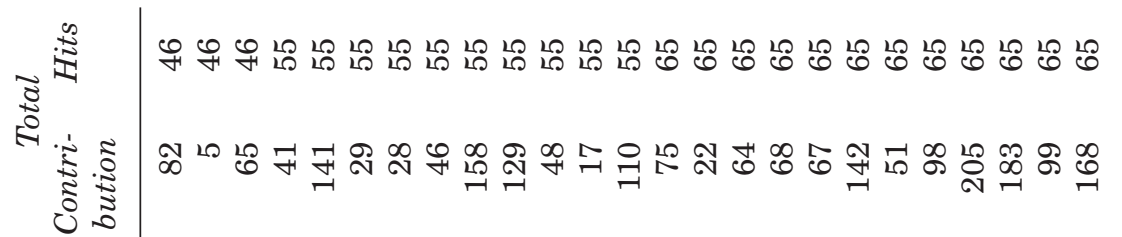

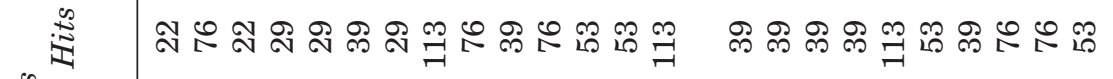

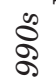
氞.

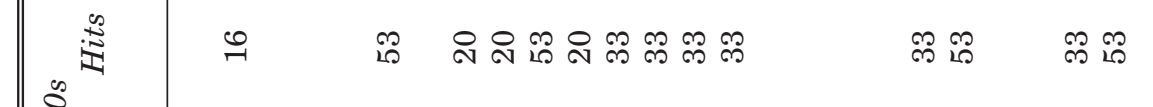

N

ลั

ลัก 녹

สิ นึ

ลิ

$\stackrel{x}{\not} \infty$

$\infty$ ล

(1)<smiles>[131IH]</smiles>

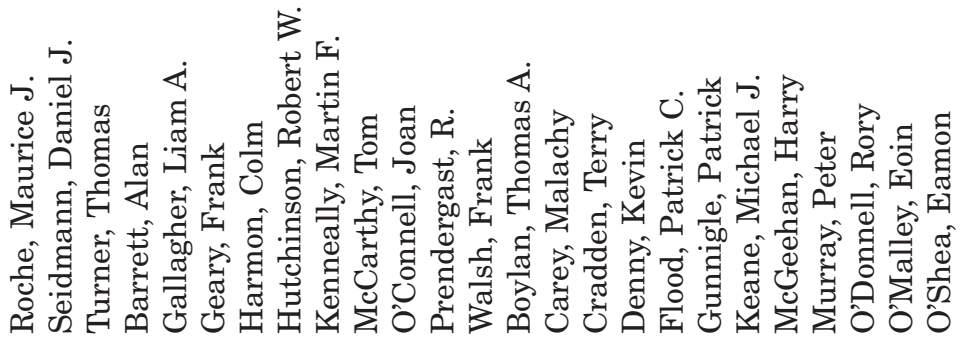




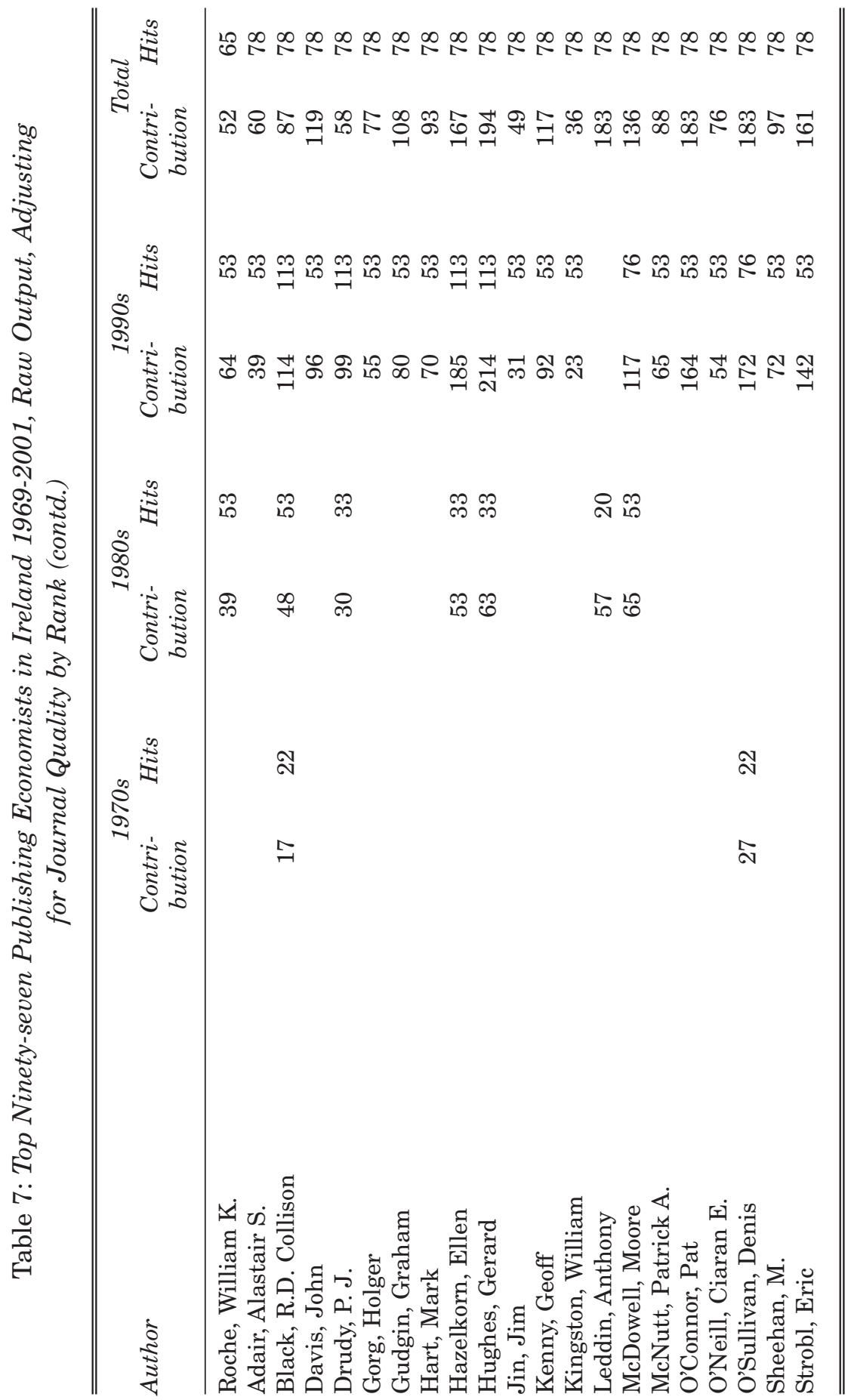


Table 8: Top 10 by Raw Rank and JCIF Adjusted Rank

\begin{tabular}{lcclcc}
\hline \hline Top 10 Raw & $\begin{array}{c}\text { Raw } \\
\text { Rank }\end{array}$ & $\begin{array}{c}\text { JCIF } \\
\text { Rank }\end{array}$ & Top 10 JCIF Adjusted & $\begin{array}{c}\text { JCIF } \\
\text { Rank }\end{array}$ & $\begin{array}{c}\text { Raw } \\
\text { Rank }\end{array}$ \\
\hline Honohan, Patrick & 1 & 2 & Neary, J. Peter & 1 & 3 \\
Borooah, Vani K. & 2 & 3 & Honohan, Patrick & 2 & 1 \\
Neary, J. Peter & 3 & 1 & Borooah, Vani K. & 3 & 2 \\
Hitchens, D. & 4 & 45 & Nolan, Brian & 4 & 7 \\
Kearney, Colm & 5 & 20 & Conniffe, Denis & 5 & 8 \\
Walsh, Brendan & 6 & 7 & Barry, Frank & 6 & 13 \\
Nolan, Brian & 7 & 4 & Walsh, Brendan & 7 & 6 \\
Conniffe, Denis & 8 & 5 & Harrison, Michael J. & 8 & 23 \\
McKillop, Donal G. & 8 & 12 & Browne, F. X. & 9 & 18 \\
O'Hagan, John W. & 10 & 18 & Ruane, Frances & 9 & 11 \\
& & & Teague, Paul & 9 & 23 \\
\hline
\end{tabular}

Table 9: Annual Productivity of Leading Economists

\begin{tabular}{lc}
\hline \hline Author & Annual Average Productivity \\
\hline Honohan, Patrick & 1.69 \\
Borooah, Vani K. & 1.91 \\
Neary, J. Peter & 1.71 \\
Hitchens, D. & 1.52 \\
Kearney, Colm & 1.72 \\
Walsh, Brendan & 0.97 \\
Nolan, Brian & 1.22 \\
Conniffe, Denis & 1.04 \\
McKillop, Donal G. & 1.93 \\
O’Hagan, John W. & 0.86 \\
Velupillai, K. V. & 1.33 \\
Ruane, Frances & 0.92 \\
Keane, Michael J. & 0.73 \\
Barry, Frank & 1.38 \\
Boyle, Gerry & 1.05 \\
Bradley, John & 0.92 \\
O’Rourke, Kevin H. & 2.00 \\
McAleese, Dermot & 0.72 \\
Geary, Patrick T. & 0.66 \\
Browne, F. X. & 0.91 \\
Lane, Philip & 3.50 \\
Ó Gráda, Cormac & 0.78 \\
\hline \hline
\end{tabular}


We made reference earlier to the distinction between longevity and productivity. We return to this issue in Table 9 where we look at the annual output of the top twenty economists listed in Table 4 . We calculate this annual average by estimating time in the profession as 2001 minus year of first publication. This may be an over-estimate for people who took time out (such as researchers starting a family, or experienced researchers taking sabbatical leave to obtain a doctorate) but it should nonetheless allow for an indicator of annual output across the group, when we divide number of hits by years in the profession.

The name that leaps out of this table is Lane, with an average annual output of 3.5 hits per year. The next highest is O'Rourke at two. What is interesting about these two individuals is that they starting publishing in the 1990s and so, as relatively new arrivals, the question arises as to whether they can maintain this rate of output. As the top three publishers (Neary, Honohan and Borooah) all increased their number of hits between the 1980s and 1990s, we might reasonably expect to see Lane and O'Rourke increasing their rate also.

\section{CONCLUSIONS}

In terms of contributions to papers that are cited in EconLit, plus those appearing in the Irish Banking Review, the Journal of the Statistical and Social Inquiry Society of Ireland and the Irish Journal of Agricultural Economics and Rural Sociology, the output of the economics profession in Ireland has expanded hugely between the 1970s and the 1990s. That expansion has been accompanied by a growing internationalisation of the output. In the $1980 \mathrm{~s}, 55$ per cent of the contributions were in the three main Irish outlets - in the 1990s, this figure had fallen to 41 per cent.

While this growth in output and growing international dimension are positive developments, other trends are less comforting for the profession in Ireland. While our reliance on domestic outlets might be falling, the authors were somewhat surprised to see this reliance at such a high level in the 1990s. Perhaps more worryingly, the overall growth in contributions has not been matched by a proportionate growth in contributions to the top journals. 


\section{REFERENCES}

BOROKHOVICH, K., R. BRICKER, K. BRUNARSKI and B. SIMPKINS, 1995. "Finance Research and Productivity", Journal of Finance, Vol 50, December, pp. 1691-1717.

BOROKHOVICH, K. and R. CHEUNG, 2000. "Finance Research: Evidence from recent graduates of doctoral programmes", Financial Practice and Education, Summer, pp. 85-92.

CHUNG, K. and R. COX, 1990. "Patterns of Productivity in the Finance Literature: a

Study of the Bibliometric Distributions", Journal of Finance, Vol. 45, No. 1, pp. 301309.

COMBES, P. and L. LINNEMER, 2001. "La publication d'articles de recherche en economie en France", Annales d'Economie et de Statistique, April-June, pp. 5-47.

COUPÉ, T., 2001. "Statistics 101 for (wannabee) economists", http://homepages.ulb.ac.be/ tcoupe/

ELLISON, GLEN, 2000. "The Slowdown of the Economics Publishing Process" NBER Working Paper W7804.

FARIA, J. R., 1998. "The Research Output of Academic Economists in Brazil”, mimeo, University of Technology, Sydney.

GRAVES, PHILLIP E., JAMES R. MARCHAND and RANDALL THOMPSON, 1982. "Economics Departmental Rankings: Research Incentives, Constraints and Efficiency", American Economic Review, December, pp. 1131-1141.

GRAVES, PHILLIP E., JAMES R. MARCHAND and RANDALL THOMPSON, 1984. "Economics Departmental Rankings: Reply and Errata", American Economic Review, Sept., pp. 834-836.

HENNESEY, E. and D. HOGAN, 2000. "Twenty-five Years of Developmental and Child Psychology in Ireland: An Analysis of PsycLit and ERIC Databases" Irish Journal of Psychology, forthcoming

HIRSCH, BARRY R., RANDALL AUSTIN, JOHN BROOKS and J. BRADLEY MOORE, 1984. "Economics Departmental Rankings: Comment", American Economic Review, Sept., pp. 822-826.

KALAITZIDAKIS, PANTELIS, THEOFANIS P. MAMUNEAS and THANASIS STENGOS, 1999. "European Economics: An Analysis Based on Publications in the Core Journals", European Economic Review, Vol. 43, pp. 1150-1168.

KING, IAN, 2000. "Rankings of Economics Departments in New Zealand" University of Auckland Department of Economics Working Paper, 9 pp.

LABAND, D. and M. PIETTE, 1994, "The Relative Impact of Economics Journals", Journal of Economic Literature, Vol. 32, pp. 640-666.

SAUER, R., 1988. "Estimates of the Returns to Quality and Coautorship in Economic Academia", Journal of Political Economy, Vol. 96, No. 4, pp. 855-866.

SCOTT, LOREN C., and PETER M. MITIAS, 1996. "Trends in Rankings of Economics Departments in the U.S.: An Update", Economic Inquiry, Vol. XXXIV, pp. 378-400.

TSCHIRHART, JOHN, 1989. "Ranking Economics Departments in Areas of Expertise", Journal of Economic Education, Spring, pp. 199-222.

ZIVNEY, TERRY and WILLIAM BERTIN, 1992. "Publish or Perish: What the Competition is Really Doing” Journal of Finance, Vol. 47 pp. 295-329. 
